\title{
ALILAÇÃo E CROTILAÇÃo CATALÍTICA E ENANTIOSSELETIVA DE ALDEÍDOS
}

Ângelo de Fátima, Luís Gustavo Robello e Ronaldo Aloise Pilli*

Departamento de Química Orgânica, Instituto de Química, Universidade Estadual de Campinas, CP 6154, 13084-971 Campinas - SP, Brasil

Recebido em 28/3/05; aceito em 14/10/05; publicado na web em 14/6/06

ENANTIOSELECTIVE CATALYTIC ALLYLATION AND CROTYLATION OF ALDEHYDES. The field of chiral catalysis has experienced explosive growth over the last two decades. By now, many of the classical reactions in organic synthesis can be carried out efficiently in asymmetric manner. As one of the fundamental and powerful C-C bond-forming reactions, enantioselective catalytic allylation (ECA) and crotylation (ECC) of aldehydes has attracted considerable attention. In this article, we present an overview about the importance of chiral Lewis acids and bases in catalytic enantioselective addition of allyl- and crotyl metals to aldehydes and the application of this methodology in the total synthesis of natural and non-natural products.

Keywords: asymmetric catalysis; allylation and crotylation; Lewis acids and bases.

\section{INTRODUÇÃO}

Atualmente a síntese orgânica tem buscado processos operacionalmente simples, seguros, ambientalmente aceitáveis, que ocorram rapidamente e de forma quantitativa quanto aos aspectos de rendimento químico e estereosseletividade, visando atingir o que P. A. Wender em 1993 denominou como síntese ideal ${ }^{1}$.

Um bom exemplo desta busca é o desenvolvimento de metodologias que empregam catalisadores ${ }^{2}$ em quantidades subestequiométricas $(<10 \mathrm{~mol} \%)$ fornecendo os produtos com alto controle enantio- e diastereoisomérico regido pelos ligantes quirais que envolvem o sítio catalítico. O desenho racional de novos ligantes é uma área que tem despertado a atenção de muitos pesquisadores que buscam desenvolver novos ligantes quirais que modulem a atividade catalítica, de forma que o produto desejado seja obtido com alta estereo-, regio- e quimiosseletividade.

As reações que envolvem a construção de ligações $\mathrm{C}-\mathrm{C}$ com o controle da configuração absoluta dos novos centros estereogênicos formados têm se mostrado uma importante ferramenta na síntese de moléculas naturais ou não-naturais. Nesse contexto incluem-se, entre outras, a reação aldólica, a adição de reagentes alil e crotilmetálicos a aldeídos e cetonas, a epoxidação, a di-hidroxilação, a redução estereocontrolada e a reação de Diels-Alder.

Nesta revisão trataremos do desenvolvimento e utilização de catalisadores em reações de adição de compostos alil e crotilmetálicos a aldeídos $^{3}$. De uma maneira geral, as abordagens dadas às metodologias catalíticas assimétricas para estas adições envolvem a ativação do eletrófilo (composto carbonílico) por ácidos de Lewis quirais, ou a ativação do nucleófilo (alil- ou crotilmetal) por bases de Lewis quirais com o objetivo de criar um ambiente quiral nestes reagentes.

As adições de espécies alilmetálicas a aldeídos apresentam um interessante aspecto no que diz respeito aos álcoois homoalílicos formados, uma vez que estes podem ser facilmente convertidos por simples oxidação do grupamento vinílico terminal aos 3hidroxialdeídos, 3-hidroxicetonas, 3-hidroxiácidos ou 1,4-dióis correspondentes, produtos estes que são empregados como blocos quirais na síntese de produtos naturais ou não-naturais que apresentam interesse biológico e/ou comercial (Figura 1).

*e-mail: pilli@iqm.unicamp.br

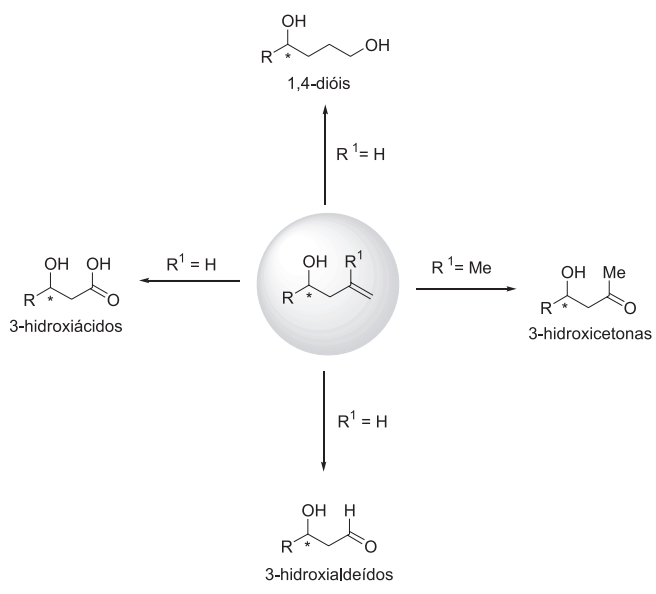

Figura 1. Possíveis conversões dos álcoois homoalílicos aos respectivos 3hidroxialdeídos, 3-hidroxiácidos, 3-hidroxicetonas ou 1,4-dióis

Os métodos catalíticos relatados empregam alilsilanos e alilestananas como agentes de alilação. Os dois principais mecanismos catalíticos envolvidos são: um mecanismo em que o complexo quiral atua como um ácido de Lewis ou uma base de Lewis quiral e outro em que ocorre a transmetalação do alilcomposto por um complexo quiral.

No primeiro caso, se o catalisador metálico quiral $\mathrm{MX}_{\mathrm{n}} \mathrm{L}^{*}$ atua como um ácido de Lewis em uma reação de alilação assimétrica, o aldeído se coordena a este complexo. A reação com alilmetal $(\mathrm{M}=$ $\mathrm{Si}, \mathrm{Sn}$ ) se processa via um estado de transição acíclico antiperiplanar $\left(\mathrm{ET}_{\mathrm{A}}\right)$, como proposto por Yamamoto para explicar a alta seletividade sin obtida na adição de crotiltributilestanana a aldeídos na presença de $\mathrm{BF}_{3} . \mathrm{OEt}_{2}$, indiferentemente da geometria da dupla ligação do crotilestanho ${ }^{4}$. Um modelo de estado de transição cíclico $\left(\mathrm{ET}_{\mathrm{B}}\right)$ é também possível para um mecanismo catalítico envolvendo um ácido de Lewis (Figura 2). Nishigaichi e Takuwa propuseram um modelo similar para adição seletiva anti de alilestananas $\gamma$-substituídas a aldeídos promovida por $\mathrm{ZnCl}_{2}{ }^{5}$. As aciloxiboranas quirais $(\mathrm{CAB})$ reagem por um mecanismo em que atuam como ácidos de Lewis, assim como os complexos de bisoxazolinas de zinco (II) e ródio (III) além de $\mathrm{Cr}$ (III). 


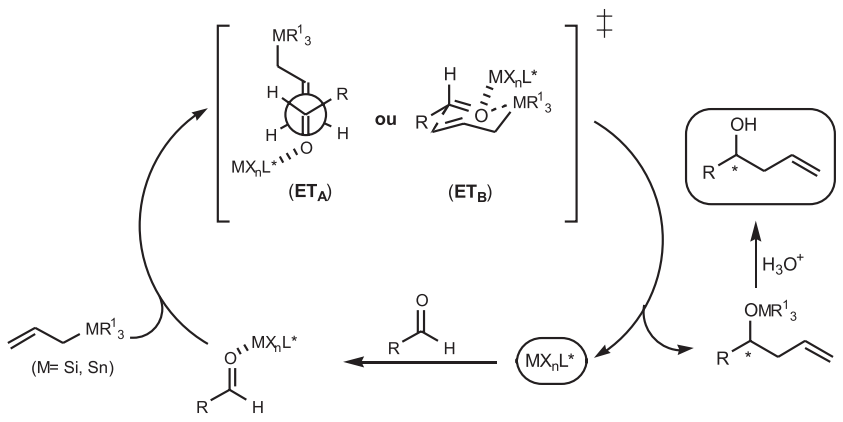

Figura 2. Possível mecanismo catalítico envolvido em reações de alilação de aldeídos com a participação de um ácido de Lewis quiral

Em um mecanismo catalisado por uma base de Lewis ocorre a coordenação do ligante quiral ao silano, ativando-o de forma que a coordenação deste complexo com o aldeído permita a transferência do grupo alil- ou crotil para o composto carbonílico, segundo um intermediário cíclico de 6 membros $\left(\mathrm{ET}_{\mathrm{C}}\right)$. Neste intermediário, o átomo de silício estaria hexacoordenado em um arranjo octaédrico totalmente organizado, permitindo a transferência de informação da geometria da dupla ligação do silano para os centros estereogênicos do álcool homoalílico (Figura 3).

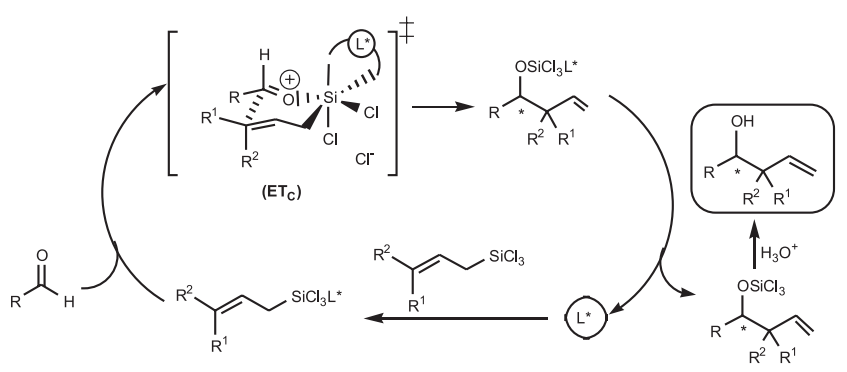

Figura 3. Possível mecanismo catalítico envolvido em reações de alilação e crotilação de aldeídos com a participação de uma base de Lewis quiral

Uma estrutura de estado de transição cíclico $\left(\mathrm{ET}_{\mathrm{D}}\right)$ contendo um ligante quiral coordenado ao átomo metálico é um provável modelo quando ocorre a transmetalação do composto alílico com o complexo $\mathrm{MX}_{\mathrm{n}} \mathrm{L}^{*}$. Este composto é, então, reintegrado ao ciclo catalítico após reação do alcoóxido metálico resultante com $\mathrm{R}_{3}^{1} \mathrm{MX}$ ( $\mathrm{M}=\mathrm{Si}$ ou $\mathrm{Sn}$ ) (Figura 4).

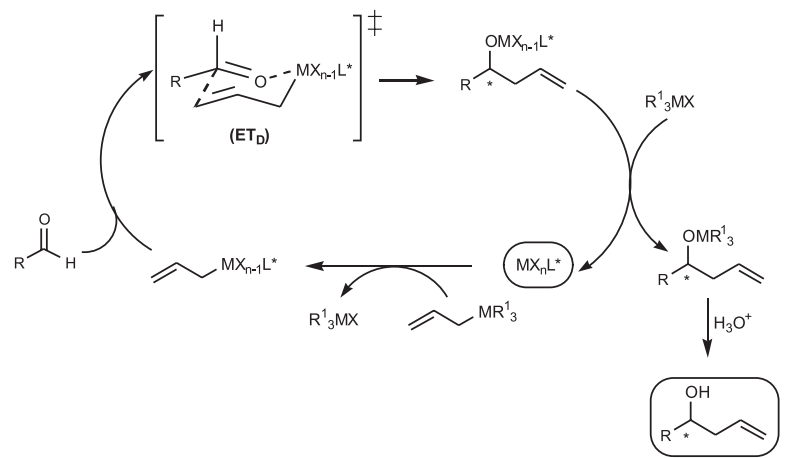

Figura 4. Possível mecanismo catalítico envolvido em reações de alilação e crotilação de aldeídos com a transmetalação do alilcomposto pelo complexo quiral

Nesta revisão descreveremos as reações catalíticas assimétricas de alilação e crotilação de aldeídos promovidas por ácidos e bases de Lewis quirais e suas aplicações em sínteses de produtos naturais ou não-naturais.

\section{ALILAÇÃO E CROTILAÇÃO CATALÍTICA ASSIMÉTRICA DE ALDEÍDOS MEDIADA POR ÁCIDOS DE LEWIS}

\section{Ligantes baseados em BINOL, BINAP e seus derivados}

Keck $^{6}$ e Tagliavini ${ }^{7}$ relataram, independentemente, o emprego de catalisadores à base de $(R)$-BINOL e Ti(IV) em reações de alilação assimétrica entre aliltribultilestananas e aldeídos. Keck e colaboradores $^{8}$, inicialmente descreveram a adição da alilestanana 1a ou $\mathbf{1 b}$ a aldeídos catalisada pelo complexo $(R)$-2, obtendo-se os respectivos álcoois homoalílicos em rendimentos moderados a excelentes e níveis de enantiosseletividade na faixa de $84-99 \%$, sendo que os aldeídos aromáticos e $\alpha, \beta$-insaturados apresentaram os melhores resultados (Esquema 1).

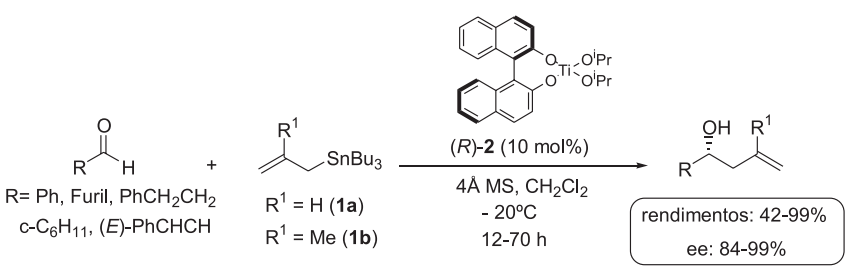

Esquema 1. Reação de alilação de aldeídos com aliltributilestanana (1a ou lb) catalisada pelo complexo $(R)-2$

O processo descrito por Keck emprega quantidades catalíticas do $\mathrm{Ti}\left(\mathrm{O}^{i} \mathrm{Pr}\right)_{4}$ e do $(R)$-BINOL, sendo este último recuperado no processo e podendo ser reutilizado sem perda da sua eficiência. Dependendo do aldeído e da estanana empregada, várias razões estequiométricas entre reagente de titânio (IV) e $(R)$-BINOL são descritas para obtenção dos respectivos produtos em rendimentos moderados a altos e excelentes excessos enantioméricos ${ }^{6,8}$.

Diferentes combinações foram avaliadas para o catalisador $(R)$ 2: i) $\mathrm{Ti}\left(\mathrm{O}^{i} \mathrm{Pr}\right)_{4} / \mathrm{BINOL}(1: 1)$ na presença de peneira molecular $(4 \AA$ MS); ii) $\mathrm{Ti}\left(\mathrm{O}^{i} \mathrm{Pr}\right)_{4} / \mathrm{BINOL}(1: 2)$ na presença de peneira molecular (4Å MS); iii) $\mathrm{Ti}\left(\mathrm{O}^{i} \mathrm{Pr}\right)_{4} / \mathrm{BINOL}(1: 2)$ na ausência de peneira

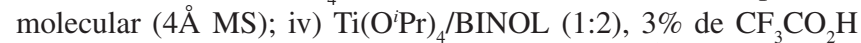
ou $\mathrm{CF}_{3} \mathrm{SO}_{3} \mathrm{H}$ na presença de peneira molecular (4£ MS).

A racionalização destas variações não está clara e não é possível indicar se estas modificações realmente levam a novos complexos de titânio. A preparação do catalisador $(R)-2$ foi descrita na presença

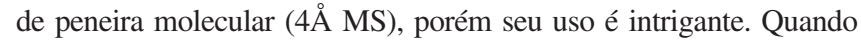
este catalisador é preparado empregando-se uma razão molar 1:2 de $\mathrm{Ti}\left(\mathrm{O}^{i} \mathrm{Pr}\right)_{4} / \mathrm{BINOL}$, não é necessário o uso de peneira molecular $(4 \AA$ MS), podendo-se realizar as reações de alilação sob condições estritamente homogêneas ${ }^{8}$. Doucet e colaboradores ${ }^{9}$ mostraram que a presença ou não de peneira molecular não influencia os rendimentos e a enantiosseletividade em reações de adição da alilestanana a aldeídos derivados do benzaldeído. Porém, Brückner e colaboradores ${ }^{10}$ realizaram um estudo sobre as reações de alilação com alilestananas $\beta$ substituídas onde mostraram que a utilização de peneira molecular (4Å MS) implicava em resultados não-reprodutíveis. A ausência de

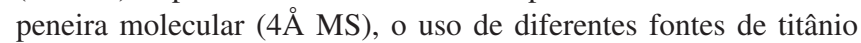
(IV) e 2 equivalentes do $(R)$-BINOL permitiram obtenção de um sistema catalítico reprodutível que rendeu os respectivos álcoois homoalílicos em bons rendimentos e excelentes enantiosseletividades. Contudo, a reatividade destes sistemas é baixa e longos períodos 
(14-70 h) são necessários para se obter resultados satisfatórios. A adição de ${ }^{i} \mathrm{PrSSiMe}_{3}{ }^{11}, \mathrm{~B}(\mathrm{OMe}){ }_{3}{ }^{12},{ }^{i} \mathrm{PrSBEt}_{2}{ }^{13}$ ou Et ${ }_{2} \mathrm{AlS}^{i} \mathrm{Pr}^{14}$ apresentou um efeito sinérgico, reduzindo o tempo de reação $(5-8 \mathrm{~h})$ sem diminuição de rendimento e do nível de enantiosseletividade.

Tagliavini e colaboradores ${ }^{7}$ desenvolveram o sistema catalítico preparado a partir de $\mathrm{TiCl}_{2}\left(\mathrm{O}{ }^{i} \mathrm{Pr}\right)_{2} \mathrm{e}(S)$ - $\mathrm{BINOL}, \mathrm{CH}_{2} \mathrm{Cl}_{2}$ à temperatura ambiente na presença de peneira molecular $(4 \AA \mathrm{MS})$. A peneira molecular é crucial para a preparação do catalisador, $(S)$-3, não sendo observada reação na sua ausência. Este sistema catalítico permite a alilação de aldeídos aromáticos em bons rendimentos, porém em níveis moderados de enantiosseletividade quando comparados com aldeídos alifáticos (Esquema 2).

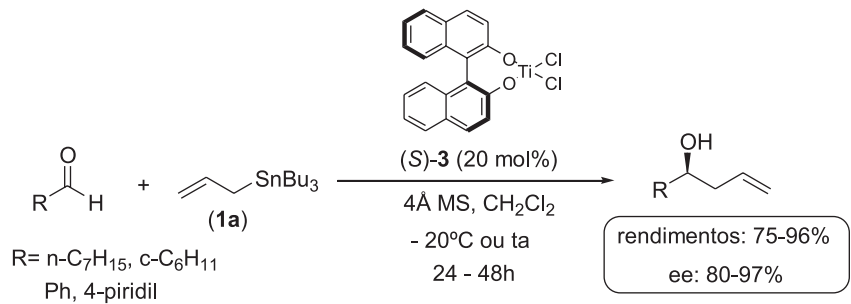

Esquema 2. Reação de alilação de aldeídos com aliltributilestanana (1a) catalisada pelo complexo (S)-3

O complexo (S)-4 desenvolvido por Carreira e colaboradores ${ }^{15}$ mostrou-se eficiente na reação de alilação de aldeídos. Contudo, a enantiosseletividade do processo é particularmente excelente apenas para aldeídos $\alpha, \alpha$-dissubstituídos (Esquema 3).

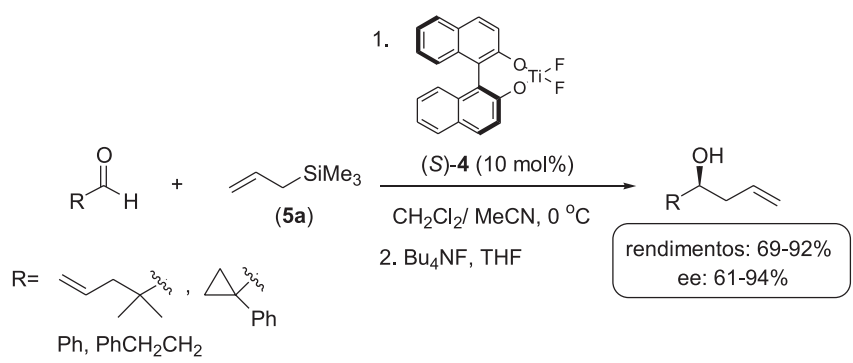

Esquema 3. Reação de alilação de aldeídos com aliltrimetilsilano (5a) catalisada pelo complexo $(S)-4$

De acordo com o protocolo de Carreira e colaboradores, os álcoois homoalílicos são obtidos em bons rendimentos e níveis de estereosseletividade. A utilização de aliltrimetilsilano $(\mathbf{5 a})^{16}$ é possível devido à maior reatividade do complexo $(S)-\mathbf{4}$. Segundo os autores, a reatividade apresentada por este complexo e sua capacidade catalítica sustentam-se na maior eletronegatividade do flúor em comparação ao cloro e ao bromo, o que torna a ligação Ti-F mais forte permitindo a permanência da espécie nucleofílica aliltrimetisilano (5a) no meio reacional. Estudos de RMN de ${ }^{1} \mathrm{H}$ para este sistema indicaram que quando 2 equivalentes de aliltrimetilsilano foram adicionados a uma solução de $(S)$-BINOL (1 equiv.) e $\mathrm{TiF}_{4}$ (1 equiv.) em $\mathrm{CD}_{2} \mathrm{Cl}_{2}$ na presença de $3 \%$ de $\mathrm{CH}_{3} \mathrm{CN}\left(0\right.$ para $\left.23{ }^{\circ} \mathrm{C}\right)$, ocorreu a formação de $\mathrm{Me}_{3} \mathrm{SiF}$ e propeno. A adição do aldeído à mistura do catalisador pré-formado leva ao aparecimento de novos sinais, que são atribuídos à formação do respectivo álcool homoalílico. Estes resultados indicaram que inicialmente o aliltrimetilsilano funciona como uma base consumindo 2 equivalentes de HF, formados na preparação do catalisador, fornecendo o propeno e o $\mathrm{Me}_{3} \mathrm{SiF}$. Não foram observados sinais correspondentes a espécies alílicas de titânio indicando que não ocorreu a transmetalação e, portanto, o complexo $(S)$-4 funciona como um ácido de Lewis quiral.

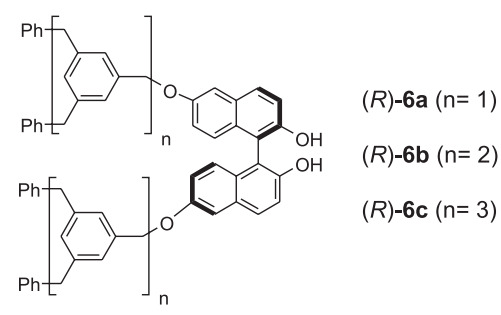

Figura 5. Estrutura dos binaftóis dendríticos desenvolvidos por Yamago e colaboradores. Adaptada da ref. 17

Implementações na utilização de sistemas catalíticos envolvendo Ti(IV) e BINOL foram descritos por Yamago e colaboradores ${ }^{17}$ que empregaram binaftóis dendríticos 6a-c como ligantes quirais (Figura 5).

$\mathrm{O}$ uso de polímeros dendríticos ${ }^{18}$ como ligantes tem recebido a atenção de alguns pesquisadores em função destes serem moléculas bem definidas e estruturalmente conhecidas ${ }^{19,20}$, podendo mimetizar reações enzimáticas altamente seletivas ${ }^{21,22}$. Podem ser utilizados como catalisadores homogêneos e são facilmente recuperados a partir da mistura reacional, utilizando-se métodos físicos (ultrafiltração ou precipitação pela ação de solventes). Os novos ligantes quirais sintetizados por Yamago e colaboradores apresentaram bons níveis de enantiosseletividade para a reação de alilação do benzaldeído (7) utilizando-se a aliltributilestana (1a), porém em baixos rendimentos ${ }^{17}$ (Esquema 4).

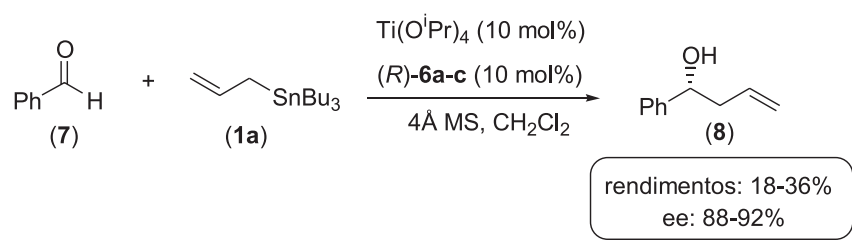

Esquema 4. Alilação assimétrica catalisada pelo complexo $T i(I V)-L^{*}\left(L^{*}=\right.$ ligantes dendríticos, $(R)-\mathbf{6} \boldsymbol{a}-\boldsymbol{c})$ )

De maneira geral, o método se mostra como uma estratégia interessante no desenho de ligantes quirais, tendo a vantagem de se recuperar facilmente o catalisador a partir do meio reacional, tornando este método atrativo para aplicação em processos industriais.

Maruoka e colaboradores ${ }^{23}$ descreveram uma interessante estratégia empregando complexos quirais bidentados de Ti(IV). A enantiosseletividade previamente relatada para a alilação do cinamaldeído $(\sim 90 \% \text { ee })^{3}$ é apenas satisfatória porque as estratégias até então empregadas se utilizam de uma simples coordenação entre um aldeído e um ácido de Lewis quiral monodentado (Figura 6, complexo A). Como conseqüência, a enantiosseletividade é diminuída pela participação de um complexo $\mathrm{B}$, no qual o grupo $\mathrm{R}$ se encontraria cis à coordenação do ácido de Lewis. O emprego de um complexo bidentado $\mathrm{C}$ como ácido de Lewis tornaria a discriminação das faces do composto carbonílico mais precisa e, conseqüentemente, maiores níveis de enantiosseletividade seriam alcançados (Figura 6).

Neste contexto, Maruoka e colaboradores ${ }^{23}$ prepararam os catalisadores quirais bidentados de titânio(IV) $[(S, S)-9 \mathbf{a}-9 d]$ a partir do (S)-BINOL (Figura 7).

Estes catalisadores mostraram-se altamente eficientes sendo capazes de acelerar a velocidade da reação de alilação quando comparados aos métodos previamente descritos ${ }^{24}$. O processo apresenta elevados níveis de enantiosseletividade além de, aparentemente, apresentar alta quimiosseletividade (entrada 13, Tabela 1).

As altas reatividade e estereosseletividade destes complexos são, 


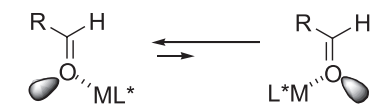

complexo A

complexo B

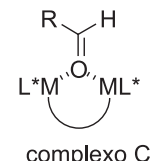

Figura 6. Coordenação de ácidos de Lewis (ML*) mono- e bidentados a aldeídos

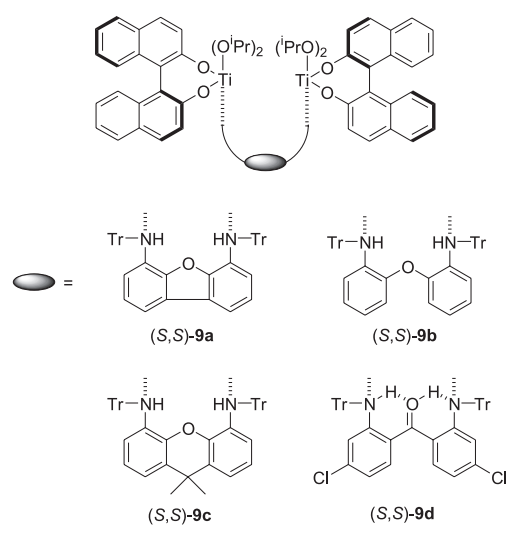

Figura 7. Estruturas dos catalisadores bidentados desenvolvidos por Maruoka e colaboradores. Adaptada da ref. 23

Tabela 1. Reação de alilação assimétrica de aldeídos com aliltribultilestanana (1a) catalisada por complexos bidentados de Ti(IV). Adaptada da ref. 23

$\stackrel{\mathrm{R}}{\mathrm{H}}_{\mathrm{H}}+\mathrm{SnBu}_{\text {(1) }} \frac{\begin{array}{c}\text { Catalisador (9a-d) } \\ (10 \mathrm{~mol} \%)\end{array}}{\mathrm{CH}_{2} \mathrm{Cl}_{2,} 0^{\circ} \mathrm{C}}$

\begin{tabular}{|c|c|c|c|c|c|}
\hline Entrada & $\mathrm{R}$ & Catalisador & $\mathrm{t}(\mathrm{h})$ & Rend. (\%) & $e e(\%)$ \\
\hline 1 & $(E)-\mathrm{PhCH}=\mathrm{CH}$ & 9a & 10 & 83 & 96 \\
\hline 2 & $(E)-\mathrm{PhCH}=\mathrm{CH}$ & $9 b$ & 10 & 85 & 96 \\
\hline 3 & $(E)-\mathrm{PhCH}=\mathrm{CH}$ & $9 \mathrm{c}$ & 10 & 81 & 96 \\
\hline 4 & $(E)-\mathrm{PhCH}=\mathrm{CH}$ & $9 d^{\mathrm{a}}$ & 5 & 88 & 97 \\
\hline 5 & $\mathrm{Ph}$ & $9 a$ & 2,5 & 94 & 98 \\
\hline 6 & $\mathrm{Ph}$ & $9 b$ & 2,5 & 67 & 97 \\
\hline 7 & $\mathrm{Ph}$ & $9 \mathrm{c}$ & 2,5 & 71 & 97 \\
\hline 8 & $\mathrm{Ph}$ & $9 d^{\text {a }}$ & 2 & 95 & 99 \\
\hline 9 & $4-\mathrm{Br}-\mathrm{C}_{6} \mathrm{H}_{4}$ & $9 a$ & 10 & 96 & 99 \\
\hline 10 & 4-Br- $\mathrm{C}_{6} \mathrm{H}_{4}$ & $9 b$ & 10 & 81 & 98 \\
\hline 11 & $4-\mathrm{Br}-\mathrm{C}_{6} \mathrm{H}_{4}$ & $9 \mathrm{c}$ & 10 & 84 & 98 \\
\hline 12 & $4-\mathrm{Br}-\mathrm{C}_{6} \mathrm{H}_{4}$ & $9 d^{a}$ & 12 & 97 & 98 \\
\hline 13 & & $9 d^{a}$ & 20 & 96 & $97^{\mathrm{b}}$ \\
\hline
\end{tabular}

a 5 mol\% do catalisador foi empregado. ${ }^{\text {b Configuração absoluta }}$ não determinada.

segundo Maruoka e colaboradores, devidas à coordenação simultânea dos dois átomos de Ti(IV) ao oxigênio carbonílico que agora se encontra duplamente ativado. Esta dupla coordenação foi demonstrada pelos autores utilizando-se estudos de efeitos NOE para o trans4-metoxi-3-buten-2-ona (10), na ausência ou na presença de complexos ácidos de Lewis mono- e bidentados (Figura 8).

Estudos de RMN da trans-4-metoxi-3-buten-2-ona (10) a bai-
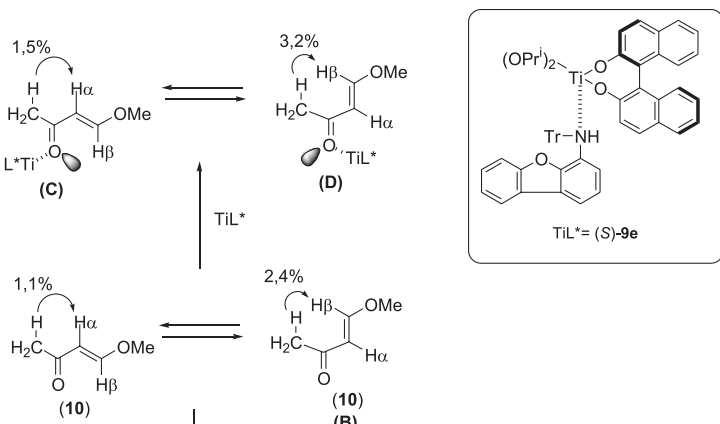

(A)

(10)
(B)
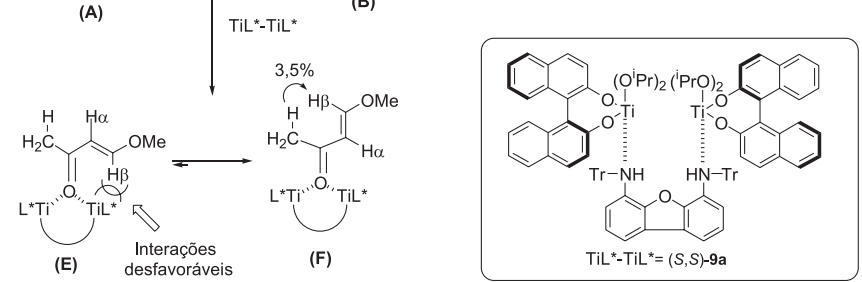

Figura 8. Equilíbrios conformacionais para trans-4-metoxi-3-buten-2-ona (10) na ausência $(\boldsymbol{A}$ e $\boldsymbol{B})$ e na presença do complexo $(S)-9 \boldsymbol{e}(\boldsymbol{C}$ e $\boldsymbol{D})$ e do complexo $(S, S)-9 a(\boldsymbol{E}$ e $\boldsymbol{F})$. Adaptada da ref. 23

xa temperatura permitem a visualização das suas conformações $s$ cis e s-trans e, portanto, a irradiação dos hidrogênios $\mathrm{CH}_{3} \mathrm{C}=\mathrm{O}$ resulta em um moderado efeito nOe para os hidrogênios $\alpha$ e $\beta$ do grupo metoxivinílico (conformações A e B). A complexação com o ácido de Lewis monodentado $(S)-9$ e resultou em efeito nOe similar para esses hidrogênios (conformações $\mathrm{C}$ e D). Porém, quando os hidrogênios $\mathrm{CH}_{3} \mathrm{C}=\mathrm{O}$ do complexo $(S, S)$-9a/enona foram irradiados, observou-se apenas efeito nOe $(3,5 \%)$ para os hidrogênios $\beta$ do grupo trans-metoxivinil, implicando a existência predominante do confôrmero s-trans (F) devido a dupla coordenação.

Recentemente, Maruoka e colaboradores ${ }^{25}$ descreveram o emprego do complexo quiral óxido de bis-Ti(IV), $(S, S)$-11, como ácido de Lewis em reações de alilação e crotilação catalítica assimétrica de aldeídos. Este complexo, que apresenta a ligação Ti-O-Ti, mostrou-se altamente eficiente para aldeídos aromáticos, $\alpha, \beta$-insaturados e alifáticos fornecendo os respectivos álcoois homoalílicos em bons rendimentos e excelentes excessos enantioméricos (Esquema 5).

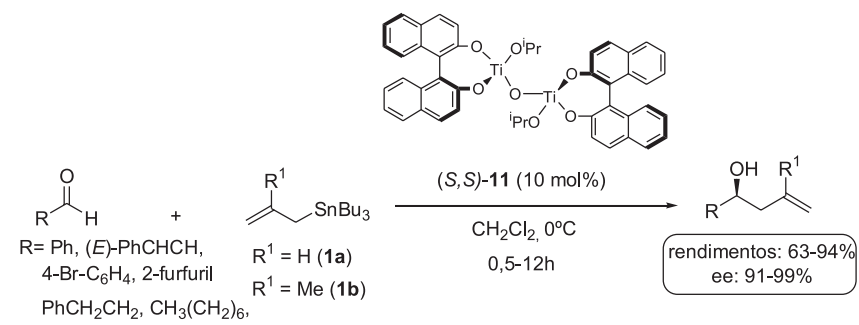
$\left(\mathrm{CH}_{3}\right)_{2} \mathrm{CH}$

Esquema 5. Reação de alilação de aldeídos com aliltributilestanana (1a ou 1b) catalisada pelo complexo $(S, S)-11$

Os autores atribuem a alta reatividade e seletividade do complexo $(S, S)$-11 à coordenação intramolecular de um oxigênio do ${ }^{i} \mathrm{PrO}-\mathrm{a}$ outro Ti, facilitando a coordenação do composto carbonílico ao $\mathrm{Ti}\left(\delta^{+}\right)$ (complexo A). Alternativamente, o oxigênio do composto carbonílico poderia se coordenar aos dois átomos de $\mathrm{Ti}$ aumentando a eletrofilicidade do aldeído (complexo B). Em ambos os casos, o complexo bis-Ti(IV) apresenta papel importante na ativação do composto carbonílico (Figura 9). 


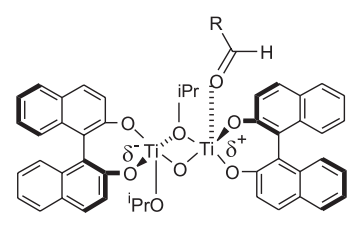

complexo A

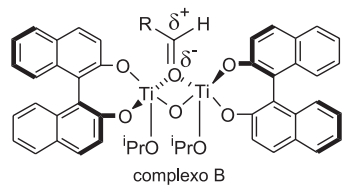

Figura 9. Possíveis complexos envolvendo o complexo (S,S)-11 na ativação de aldeídos. Adaptada da ref. 25

Os catalisadores baseados em zircônio, BINOL-Zr(IV $)^{26}$, desenvolvidos por Tagliavini são mais reativos que $(R)-\mathbf{2}$ (segundo procedimento original de $\mathrm{Keck}^{8}$ ) e mostraram igual eficiência quando comparados a $(R)-2$ para aldeídos $\alpha, \beta$-insaturados e aromáticos. Contudo mostraram baixa eficiência (rendimento e enantiosseletividade) com aldeídos alifáticos (Esquema 6).

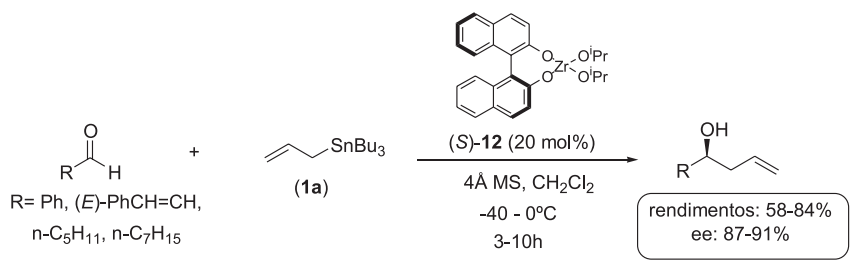

Esquema 6. Reação de alilação assimétrica de aldeídos com aliltribultilestanana (1a) catalisada por complexo (S)-12

A adição de calix[4]areno em quantidades catalíticas no processo de preparação de catalisadores de zircônio (IV) foi realizada por Tagliavini e colaboradores ${ }^{27}$, que empregaram $\mathrm{ZrCl}_{4}$ (thf) ${ }_{2}$ como ácido de Lewis, $(S)$-BINOL e 4-terc-butilcalix[4]areno em uma razão de 1:1:1. Este sistema catalítico, diferentemente de $(S)-\mathbf{1 2}$, permitiu obter altos excessos enantioméricos para aldeídos alifáticos usando apenas 2-5 mol\% do promotor quiral. No entanto, baixa eficiência continuou a ser observada para aldeídos $\alpha, \beta$-insaturados e aromáticos (Tabela 2) quando comparados a $(S)$-12 sem a adição de 4-terc-butilcalix[4]areno.

Tabela 2. Reação de alilação assimétrica de aldeídos com aliltribultilestanana 1a catalisada pelo complexo $(S)$-12 e 4-tercbutilcalix[4]areno. Adaptada da ref. 27

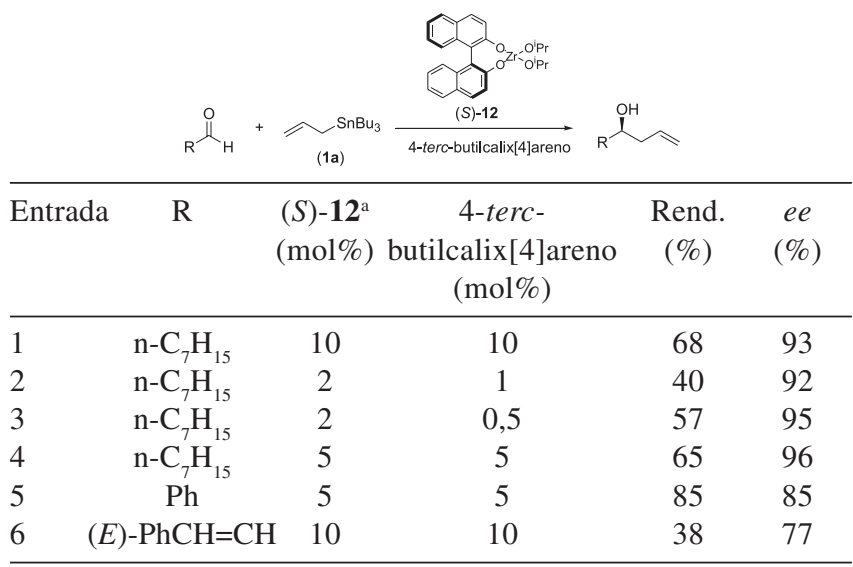

${ }^{a}$ Para todas as reações, a razão molar entre $\mathrm{ZrCl}_{4}(\text { thf })_{2}$ e BINOL foi de $1: 1$.

$\mathrm{O}$ uso de tetra-terc-butóxido de zircônio, $\mathrm{Zr}\left(\mathrm{O}^{\prime} \mathrm{Bu}\right)_{4}$, como ácido de Lewis mostrou-se mais eficiente quando comparado ao $\mathrm{ZrCl}_{4}$ (thf) ou $\mathrm{Zr}\left(\mathrm{O}^{\mathrm{i} P r}\right)_{4}{ }^{28}$. Kurosu e Lorca $^{28}$ prepararam o catalisador $(S)-\mathbf{1 3}$ a partir de uma razão 1:1,2 de $(S)$-BINOL e $\mathrm{Zr}\left(\mathrm{O}^{\prime} \mathrm{Bu}\right)_{4}$, respectivamente. $\mathrm{O}$ uso de peneira molecular e pivalonitrila como co-solvente mostrou-se essencial. $\mathrm{O}$ processo apresentou-se eficiente para aldeídos alifáticos, aromáticos e $\alpha, \beta$-insaturados (Esquema 7).

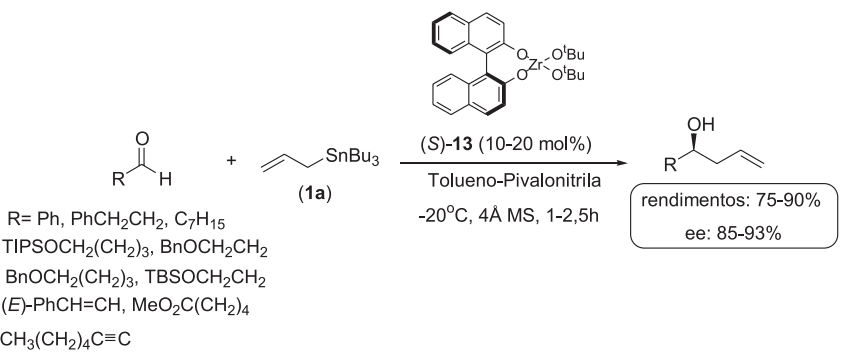

Esquema 7. Reação de alilação de aldeídos com aliltributilestanho (1a) catalisada pelo complexo (S)-13

A metodologia foi estendida para alilação de $\beta$-alcoxialdeídos quirais (14a-e). A diastereosseletividade do processo mostrou-se dependente dos grupos de proteção $(\mathrm{P})$ na posição $\beta$ sendo o grupo MOM o mais apropriado para as reações descritas ${ }^{28}$ (Tabela 3 ).

Tabela 3. Reação de alilação assimétrica de $\beta$-alcoxialdeídos com aliltribultilestanana 1a catalisada pelo complexo $(S)$-13. Adaptada da ref. 28
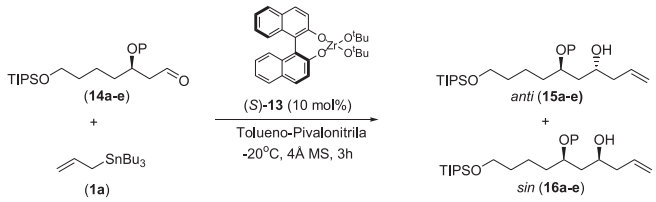

(1a)

\begin{tabular}{llcc}
\hline Entrada & \multicolumn{1}{c}{ Aldeídos } & Seletividade $($ anti/sin $)$ & Rend. $(\%)$ \\
\hline 1 & 14a $(\mathrm{P}=\mathrm{Me})$ & $2 / 1$ & 90 \\
2 & 14b $(\mathrm{P}=\mathrm{MOM})$ & $1 / 8$ & 90 \\
3 & 14c $(\mathrm{P}=\mathrm{Bn})$ & $1 / 1$ & 80 \\
4 & 14d $(\mathrm{P}=\mathrm{PMB})$ & $1 / 1$ & 88 \\
5 & 14e $(\mathrm{P}=\mathrm{TBS})$ & $1 / 1$ & 85 \\
$6^{\mathrm{a}}$ & 14b $(\mathrm{P}=\mathrm{MOM})$ & $8 / 1$ & 85 \\
\hline
\end{tabular}

${ }^{a}(R)$-BINOL foi empregado. Siglas: MOM (metoximetil), PMB ( $p$-metoxibenzil) e TBS (terc-butildimetilsilil).

Para os complexos $(R)-\mathbf{2},(S) \mathbf{3},(S) \mathbf{- 4},(S)$-12 os autores observaram o fenômeno de amplificação assimétrica ${ }^{29}$ implicando que, no mínimo, em algum estágio do processo, mais de uma molécula do ligante quiral estaria coordenada ao centro metálico. Em um estudo inicial, Faller e colaboradores ${ }^{30}$ demonstraram o efeito nãolinear positivo apresentado pelo complexo $(R)-\mathbf{2}$ para a reação de alilação do benzaldeído (7) (Figura 10) e, posteriormente, empregaram uma mistura racêmica do complexo Ti(IV)/ BINOL na presença de um complexo opticamente puro de Ti(IV)/(D)-tartarato de di-isopropila, obtendo bons níveis de enantiosseletividade (Tabela 4). A possibilidade da utilização de ligantes quase racêmicos é um aspecto interessante quando consideramos a quantidade exigida em um processo industrial e o alto custo associado a estes ligantes.

Os resultados obtidos por Faller e colaboradores empregando uma mistura racêmica do complexo Ti(IV)/BINOL na presença de um complexo opticamente ativo de Ti(IV)/ (D)-tartarato de di- 
Tabela 4. Reação de alilação assimétrica de aldeídos com aliltribultilestanana (1a) catalisada por uma mistura racêmica do complexo Ti(IV)/BINOL na presença de um complexo opticamente ativo de Ti(IV)/(D)-tartarato de di-isopropila [(D)-DIPT]. Adaptada da ref. 30

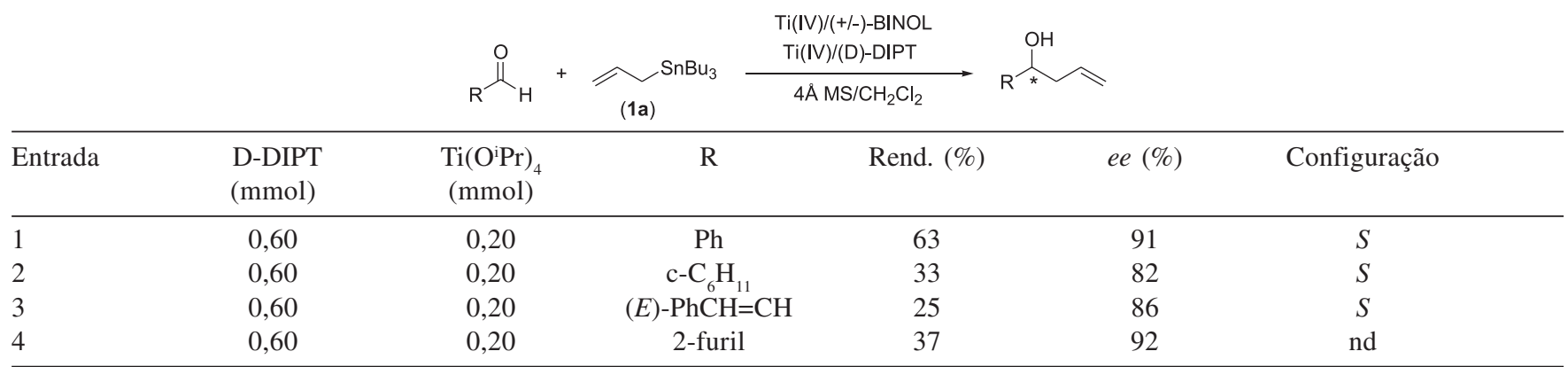

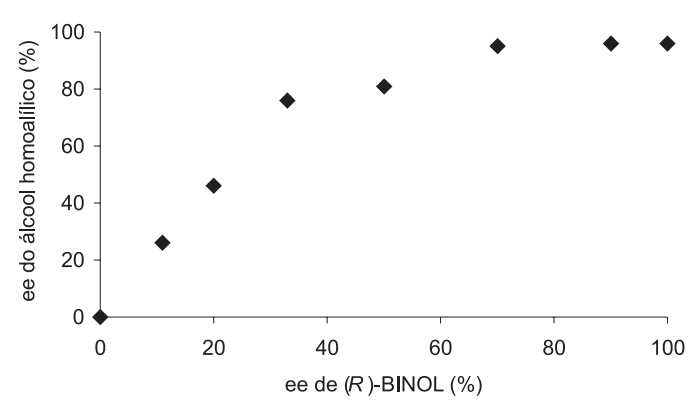

Figura 10. Efeito não-linear positivo observado para o complexo $(R)-2$ na reação de alilação do benzaldeído (7) utilizando-se aliltributilestanana

isopropila é, segundo eles, conseqüência do envenenamento quiral em função da formação de espécies mistas 19 e 20 (Figura 11, Tabela 4). É possível que uma das espécies mistas seja estável e inativa, enquanto a outra seja a espécie cataliticamente ativa ${ }^{31}$ ou que se dissocia em um monômero ativo pela coordenação ao aldeído ${ }^{32}$.

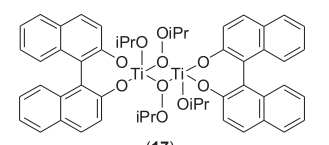

(17)

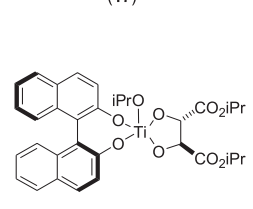

(19)

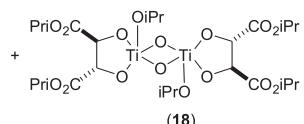

(18)

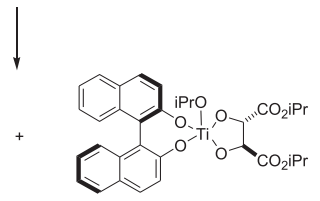

(20)
Figura 11. Estruturas das possiveis espécies mistas (19 e 20) envolvidas na reação de alilação de aldeídos utilizando-se aliltributilestanana e uma mistura racêmica do complexo Ti(IV)/BINOL (17) na presença de um complexo opticamente ativo de $T i(I V) /(D)-D I P T(18)$

Yamamoto e colaboradores investigaram a alilação de aldeídos com aliltributilestana (1), catalisada por complexos metálicos do $(S)$ BINAP $^{33}$ e $(R)$ - $p$-Tol-BINAP ${ }^{34}$ com triflato de prata (AgOTf) ou fluoreto de prata $(\mathrm{AgF}),(S)-21$ e $(R)-\mathbf{2 2}$, respectivamente. Esta metodologia permitiu obter altos rendimentos e consideráveis enantiosseletividades para aldeídos aromáticos e $\alpha, \beta$-insaturados, mas baixos rendimentos e apenas moderado estereocontrole para aldeídos alifáticos ${ }^{33,34}$ (Tabela 5).

$\mathrm{O}$ uso de trialcoxisilanos alílicos, em substituição às correspondentes estananas, mostrou-se uma importante modificação quando consideramos a toxicidade destas últimas. Até o presente momento o mecanismo envolvido nestes e nos demais processos apresentados até aqui não estão esclarecidos.
Tabela 5. Reação de alilação assimétrica de aldeídos com aliltribultilestanana (1a) ou aliltrimetoxisilano (23a) catalisada pelos complexos $(S)$-21 e $(R)$-22. Adaptada das refs. 33 e 34

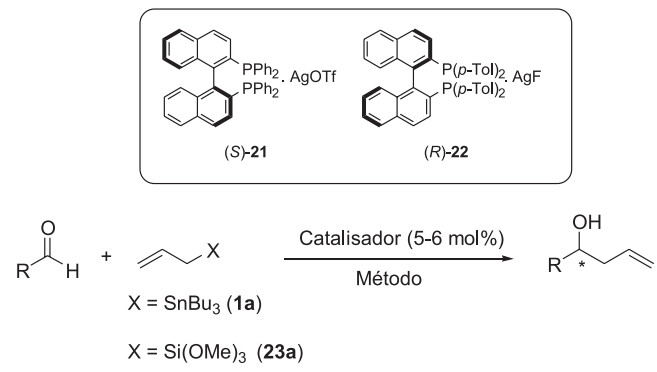

\begin{tabular}{lccccc}
\hline Entrada & $\mathrm{R}$ & $\begin{array}{c}\text { Método }^{\mathrm{a}} \\
{[\text { Catalisador }]}\end{array}$ & Alil & $\begin{array}{c}\text { Rend. } \\
(\%)\end{array}$ & $\begin{array}{c}e e(\%) \\
{[\text { Conf. }]}\end{array}$ \\
\hline 1 & $\mathrm{Ph}$ & A $[(S)-21]$ & $\mathbf{1 a}$ & 88 & $96[S]$ \\
$2^{\mathrm{b}}$ & $\mathrm{Ph}$ & B $[(R)-\mathbf{2 2}]$ & $\mathbf{2 3 a}$ & 80 & $94[R]$ \\
$3^{\mathrm{c}}$ & $(E)-\mathrm{PhCH}=\mathrm{CH}$ & A $[(S)-21]$ & $\mathbf{1 a}$ & 83 & $88[S]$ \\
$4^{\mathrm{d}}$ & $2-$ furil & A $[(S)-21]$ & $\mathbf{1 a}$ & 94 & $93[S]$ \\
5 & $2-$ furil & B $[(R)-22]$ & $\mathbf{2 3 a}$ & 70 & $83[R]$ \\
6 & $4-\mathrm{Br}-\mathrm{C}_{6} \mathrm{H}_{4}$ & B $[(R)-\mathbf{2 2}]$ & $\mathbf{2 3 a}$ & 90 & $93^{\mathrm{e}}$ \\
\hline
\end{tabular}

${ }^{a}$ Método A: A reação foi realizada utilizando-se $(S)$-BINAP.AgOTf ( 0,05 equiv.), aliltribultilestanana (1,0 equiv.) e aldeído ( 1,0 equiv.) em THF à $-20{ }^{\circ} \mathrm{C}$ por $8 \mathrm{~h}$. Método B: A reação foi realizada utilizando-se ( $R$ )-p-Tol-BINAP (0,06 equiv.), $10 \mathrm{~mol} \%$ de $\mathrm{AgF}$, aliltrimetoxisilano (1,5 equiv.) e aldeído (1,0 equiv.) em metanol à $-20{ }^{\circ} \mathrm{C}$ por $4 \mathrm{~h}$. bUtilizou-se $3 \mathrm{~mol} \%$ do $(R)$-p-Tol-BINAP e $5 \mathrm{~mol} \%$ de AgF. 3,0 equivalentes de tributilestanana foram empregados. d3,0 equivalentes de tributilestanana e 0,2 equivalentes do $(S)$ BINAP.AgOTf foram empregados. ${ }^{\mathrm{e} A}$ configuração absoluta é desconhecida.

A adição de $(E)$ e (Z)-crotiltrimetoxisilanos a aldeídos catalisada pelo complexo $(R)$-BINAP/AgF, $(R)$-24, forneceu, em ambos os casos, o aduto $\gamma$ com uma razão anti/sin de 92/8 e 94/6, respectivamente. $\mathrm{O}$ uso de uma mistura aproximadamente $1: 1$ de $(E)$ e $(Z)$ trialcoxidosilanos também forneceu resultado similar em favor do isômero anti (Tabela 6).

Estudos de RMN de ${ }^{13} \mathrm{C}$ de uma mistura 1:1 de crotiltrimetoxilsilano, $(R)$-BINAP/AgF e DMF em $\mathrm{CH}_{3} \mathrm{OD}$ à temperatura ambiente mostraram a ausência dos sinais referentes ao crotiltrimetoxilsilano. Estes resultados indicam a ocorrência de transmetalação, fornecendo espécies crotilprata(I). Se uma subseqüente isomerização do $(Z)$-crotilprata para o isômero $(E)$ ocorre mais rapidamente que a reação com o aldeído, o álcool homoalílico anti pode ser obtido como produto majoritário, a partir de $(E)$ - ou $(Z)$ - 
Tabela 6. Adição de $(E)$ e $(Z)$-crotiltrimetoxisilanos a benzaldeído (7) catalisada pelo complexo $(R)$-BINAP/ AgF, $(R)$-24. Adaptada da ref. 34

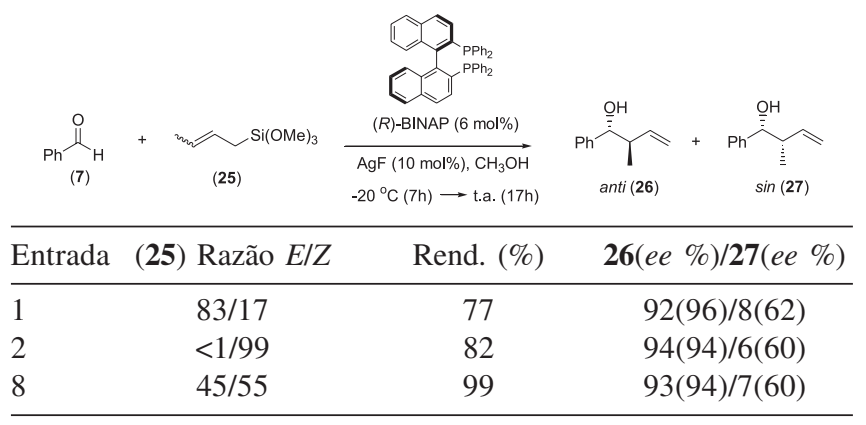

crotiltrimetoxisilanos, via o estado de transição A que minimiza interações 1,3-alílicas (Figura 12).
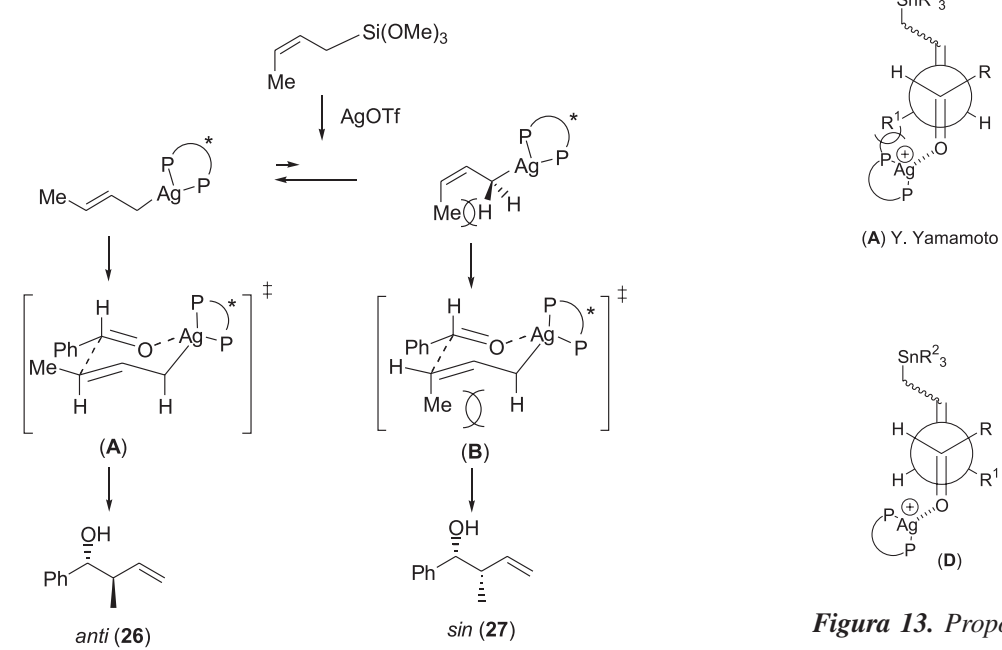

Figura 12. Estruturas dos estados de transição para obtenção dos álcoois homoalílicos 26 e 27

O emprego da crotilestanana $(E)$-1c também forneceu exclusivamente o produto alilado com razão anti/sin de $85 / 15$ e um excesso enantiomérico de $94 \%$ em favor do isômero anti quando foi empregado o complexo $(R)$-BINAP/AgOTf, $(R)$-28. Resultados similares foram obtidos para $(Z)$-crotilestanana $(E / Z=2 / 98)$ ou para uma mistura aproximadamente $1: 1$ de $(E)$ - e $(Z)$-crotilestanana, porém a razão anti/sin foi inferior quando comparada aos análogos crotiltrimetoxisilanos (25) (Tabela 7).

Diferentemente do catalisador $(R)-\mathbf{2 4}$, o mecanismo catalítico para

Tabela 7. Adição de $(E)$ e $(Z)$-crotilestananas a aldeídos catalisada pelo complexo $(R)$-BINAP/ AgOTf, $(R)$-28. Adaptada da ref. 33

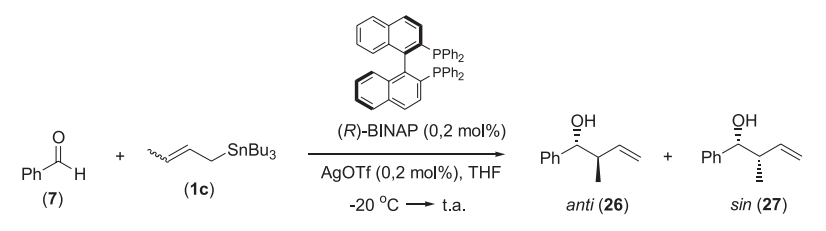

\begin{tabular}{lccc}
\hline Entrada & (1c) Razão E/Z & Rendimento (\%) & $\mathbf{2 6}(e e \%) / \mathbf{2 7}(e e \%)$ \\
\hline 1 & $95 / 5$ & 56 & $85(94) / 15(64)$ \\
2 & $2 / 98$ & 72 & $85(91) / 15(50)$ \\
3 & $53 / 47$ & 45 & $85(94) / 15(57)$ \\
\hline
\end{tabular}

(A) Y. Yamamoto

o catalisador $(R)$-BINAP/AgOTf não foi completamente elucidado. Quando o complexo $(R)$-BINAP/AgOTf foi tratado com uma quantidade equimolar de aliltributilestanana em THF a $20{ }^{\circ} \mathrm{C}$ seguido da elaboração da metade da mistura inicial, foi possível recuperar $98 \%$ do composto alilestanho (baseado em $50 \%$ da estanana presente na metade da mistura reacional). A outra metade foi tratada com um equivalente do benzaldeído a $-20{ }^{\circ} \mathrm{C}$ por $8 \mathrm{~h}$, fornecendo o álcool homoalílico em $35 \%$ de rendimento e $>99 \%$ de excesso enantiomérico. Estes resultados mostraram que a alilação não se processa via a transmetalação da espécie alilestanho. Não está clara a razão da seletividade anti, porém alguns modelos podem ser invocados para esclarecer alguns aspectos da reação. Para a seletividade $\sin$, Yamamoto propôs um estado de transição antiperiplanar do tipo A, enquanto Keck sugere uma estrutura sinclinal do tipo $\mathbf{B}$ para explicar a seletividade $\sin$ para (E)-estananas ${ }^{35}$ (Figura 13).

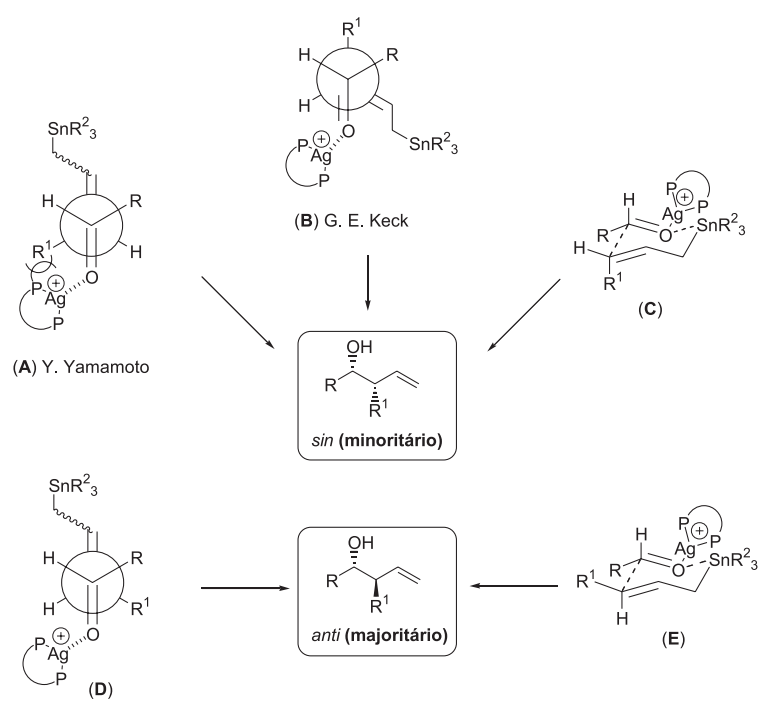

Figura 13. Propostas de estados de transição para reações de alilação de aldeídos por alilestananas catalisada pelo complexo $(R)$-BINAP/AgF, $(R)$ 24, e pelo complexo (R)-BINAP/AgOTf, $(R)-28$

As reações de alilação anti seletivas envolvendo o complexo $(R)$ 24 devem proceder via um estado de transição acíclico antiperiplanar do tipo $\mathbf{D}$, que apresenta menores interações estéricas entre o ácido de Lewis e o carbono estanilmetilênico e/ou ao grupo $\mathrm{R}^{1}$ da alilestanana. Um estado de transição cíclico do tipo $\mathbf{E}$ envolvendo um ácido de Lewis $^{5}$ que levaria ao produto anti é também possível, bem como um estado de transição cíclico do tipo $\mathbf{C}$ que leva ao produto sin que, diferentemente de $\mathbf{E}$, é desfavorecido em razão de interações envolvendo o grupo $R^{1}$. A evidência de que não ocorre transmetalação para a aliltributilestanana suporta o envolvimento do complexo $(R)-\mathbf{2 4}$ como um ácido de Lewis, porém o tratamento de um equivalente da $(Z)$ crotilestanana $(E / Z=7 / 93)$ com benzaldeído na presença de uma solução $0,2 \mathrm{M}$ de $(R)-\mathbf{2 4}$ em THF a uma temperatura de -20 a $20{ }^{\circ} \mathrm{C}$ por 24 $\mathrm{h}$ forneceu uma mistura de 14/86 da (E)-e (Z)-crotilestanana em $47 \%$ de rendimento e uma mistura dos álcoois homoalílicos em $30 \%$ de rendimento com uma razão anti/sin de 86/14. Um mecanismo por transferência de elétrons é também aceitável. Contudo, até o presente momento não existem evidências experimentais deste processo.

$\mathrm{O}$ catalisador de Yamamoto, em sua forma modificada, foi recentemente empregado em reação de alilação assimétrica e catalítica em um sistema aquoso ${ }^{36}$ utilizando-se uma mistura de $\mathrm{H}_{2} \mathrm{O} / \mathrm{EtOH}$ (1:9). $\mathrm{O}(S)$-Tol-BINAP/AgNO 3 [(S)-29] foi empregado na quantidade de 10 mol\%, fornecendo razoáveis níveis de enantiosseletividade apenas para aldeídos aromáticos (58-81\% ee; $88-100 \%$ de rendimento) ${ }^{37}$. 
Na tentativa de se encontrar um sistema catalítico capaz de fornecer melhores rendimentos e níveis de enantiosseletividade, Yamamoto e colaboradores ${ }^{38}$ relataram o uso de aditivos $(\mathrm{KF} / 18$ Crown-6) em conjunto com o sistema $(R)$-BINAP/AgOTf $[(R)-21]$ na reação de alilação entre aliltrimetoxisilano (23a) e vários aldeídos aromáticos, $\alpha, \beta$-insaturados e alifáticos em condições reacionais otimizadas (Esquema 8). O emprego de aditivos mostrou-se potencialmente interessante uma vez que forneceu os respectivos produtos de alilação em melhores rendimentos e enantiosseletividades quando comparados ao mesmo método sem a utilização de aditivos.

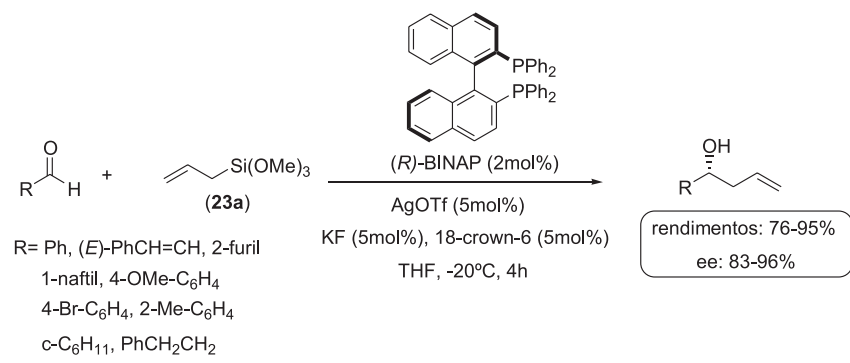

Esquema 8. Reação de alilação de aldeídos com aliltrimetoxisilano (23a) catalisada pelo sistema $(R)$-BINAP/AgOTf, $(R)-21$, na presença de aditivos

Outros ligantes quirais derivados do BINAP (Figura 14) foram testados na reação entre benzaldeído e aliltrimetoxisilano (23a), porém todos apresentaram-se menos eficientes que o BINAP, tanto no rendimento quanto na enantiosseletividade da reação em questão ${ }^{38}$.

Recentemente, Shi e colaboradores ${ }^{39}$ investigaram o emprego

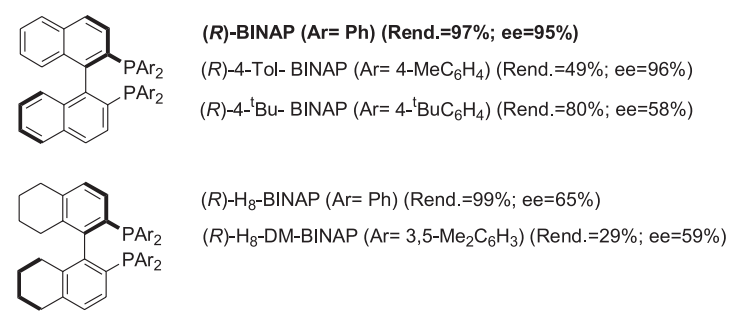

Figura 14. Efeitos de alguns ligantes quirais derivados do BINAP no rendimento e enantiosseletividade da reação entre benzaldeído (7) e aliltrimetoxisilano (23a). Adaptada da ref. 38 catalítico de ligantes quirais derivados de bis-naftiltiofosforamidas no sistema $\operatorname{Ag}(\mathrm{I}) / \mathrm{L} *$ como indutor de quiralidade em reações de alilação enantiosseletiva de aldeídos na presença da alilestanana (1a). Porém, apenas aldeídos aromáticos e $\alpha, \beta$-insaturados foram testados e moderados rendimentos e níveis de enantiosseletividade foram observados (Esquema 9).

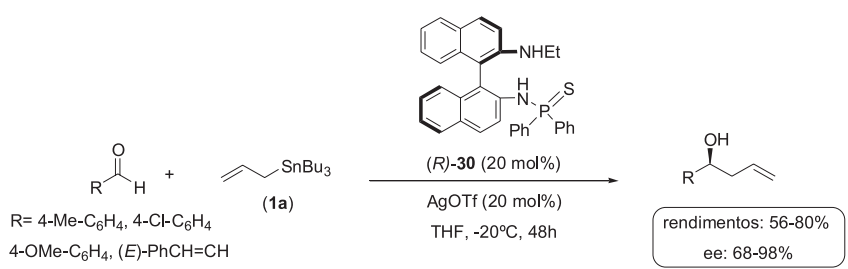

Esquema 9. Reação de alilação de aldeídos com aliltributilestanho (1a) catalisada pelo sistema $(R)-30 / A g O T f$

\section{Ligantes baseados em aciloxiboranas quirais (CAB)}

Yamamoto e colaboradores ${ }^{40}$ foram os primeiros a relatar, em 1991, uma reação de alilação enantiosseletiva e catalítica usando aciloxiboranas quirais (CAB) como catalisadores. Aciloxiboranas quirais são preparadas a partir do ácido tartárico como mostrado no Esquema 10.
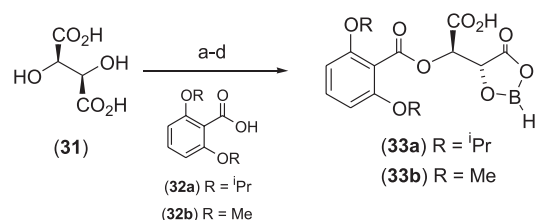

a) $\mathrm{BnBr}, \mathrm{DBU}, \mathrm{DMF}$. b) DMAP, 32a ou 32b, DCC, $\mathrm{CH}_{2} \mathrm{Cl}_{2}, 0^{\circ} \mathrm{C}$ c) $10 \% \mathrm{Pd} / \mathrm{C}, \mathrm{AcOEt}, \mathrm{H}_{2}$ (ca $100 \%$ ). d) DMAP, DCC, $\mathrm{CH}_{2} \mathrm{Cl}_{2}, 0^{\circ} \mathrm{C}$ e) $\mathrm{BH}_{3} . \mathrm{THF}, \mathrm{C}_{2} \mathrm{H}_{5} \mathrm{CN}, 0^{\circ} \mathrm{C}, 1 \mathrm{~h}$.

Esquema 10. Preparação das aciloxiboranas quirais (CAB) $\mathbf{3 3 a}$ e $\mathbf{3 3 b}$. Adaptado da ref. 40

As reações de alil- e crotilsilanos a aldeídos, catalisadas por $\mathrm{CAB}$, mostram que são altamente sin-diastereo e enantiosseletivas, diferentemente do que foi observado para os sistemas que empregam BINOL e BINAP como ligantes quirais (Tabela 8).

Tabela 8. Reações de alilação de aldeídos com alil- e crotilsilanos catalisadas por CAB-33A. Adaptada da ref. 41

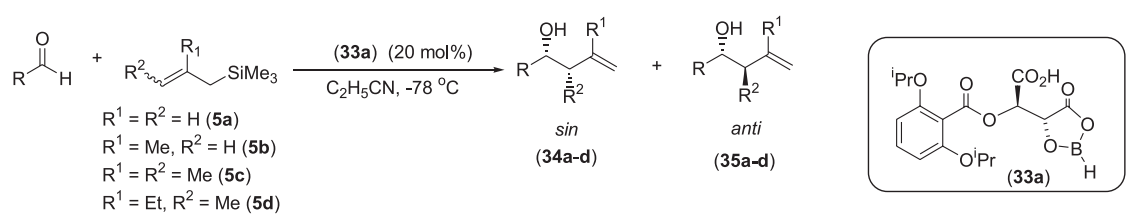

\begin{tabular}{|c|c|c|c|c|c|}
\hline Entrada & $\mathrm{R}$ & Silano & Rend. (\%) & sin/anti & $e e(\%)$ [Produto] \\
\hline $1^{\mathrm{a}}$ & $\mathrm{Ph}$ & $5 \mathbf{a}$ & 46 & - & $55[\mathbf{3 4 a}]$ \\
\hline 2 & $\mathrm{Ph}$ & $5 \mathbf{b}$ & 68 & - & $82[\mathbf{3 4 b}]$ \\
\hline 3 & $\mathrm{Ph}$ & $5 c^{b}$ & 63 & $96 / 4$ & $92[\mathbf{3 4 c}]$ \\
\hline 4 & $\mathrm{C}_{4} \mathrm{H}_{9}$ & $5 c^{b}$ & 30 & $94 / 6$ & $85[34 c]$ \\
\hline 5 & $\mathrm{Ph}^{9}$ & $5 d$ & 74 & $97 / 3$ & $96[\mathbf{3 4 d}]$ \\
\hline $6^{c}$ & $\mathrm{Ph}$ & $5 d$ & 81 & $97 / 3$ & $96[\mathbf{3 4 d}]$ \\
\hline 7 & $(E)-\mathrm{CH}_{3} \mathrm{CH}=\mathrm{CH}$ & $5 d$ & 21 & $95 / 5$ & 89 [34d] \\
\hline 8 & $\mathrm{C}_{3}^{3} \mathrm{H}_{7}$ & $5 d$ & 36 & $95 / 5$ & $86[\mathbf{3 4 d}]$ \\
\hline
\end{tabular}

${ }^{\mathrm{a}} \mathrm{A}$ reação foi realizada a $-20{ }^{\circ} \mathrm{C}$. ${ }^{\mathrm{b}}$ Mistura dos dois isômeros $(E / Z=61 / 39)$ foi empregada. ${ }^{\mathrm{c}} \mathrm{A}$ aciloxiborana derivada do $(S, S)$-ácido tartárico foi empregada. 
Como pode ser observado, a estereoquímica relativa dos produtos de adição independe da geometria da dupla do organosilano e o processo é altamente sin seletivo. Estes resultados são similares aos observados com $\mathrm{BF}_{3} \cdot \mathrm{OEt}_{2}$ em reações de adição de alilestananas a aldeídos ${ }^{41}$. Um estado de transição acíclico é proposto onde a preferência sin/anti é resultado de interações estéreas envolvendo os grupos R e R ${ }^{2}$ (Figura 15).

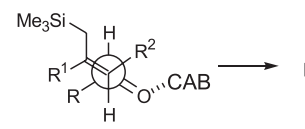

(A)

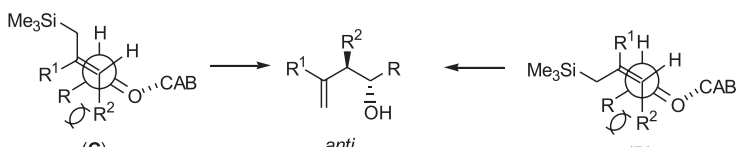

(C)

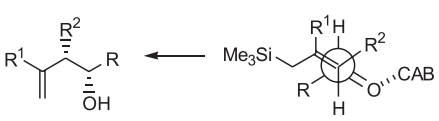

(B)

(D)
Figura 15. Estados de transição para a adição de alilsilanos a aldeídos catalisada por $C A B$

De acordo com os possíveis modelos de estados de aproximação, $\mathbf{A}$ e $\mathbf{B}$ seriam favorecidos sobre $\mathbf{C}$ e $\mathbf{D}$ levando à seletividade sin desta reação. $\mathrm{O}$ exato mecanismo pelo qual as aciloxiboranas controlam a preferência facial da adição ainda não foi elucidado com base em evidências experimentais.

Marshall e colaboradores ${ }^{42}$ demonstraram que as reações de crotilação de aldeídos catalisadas por $\mathrm{CAB}$ podem fornecer melhores rendimentos quando se empregam crotilestananas e 2,0 equivalentes de ácido trifluoroacético. Posteriormente, realizaram um estudo comparativo entre o catalisador do Keck [(R)-2] e CAB33b para as reações de alilação e crotilação catalítica e assimétrica do cicloexanocarboxialdeído (36) com alil- e crotilestananas, 1a e 1c (Tabela 9). Quando foi empregada a crotilestanana 1c, o catalisador CAB-33b mostrou-se mais eficiente quando comparado ao catalisador $(R)-2$ apresentando melhor rendimento e razão diastereoisomérica ${ }^{43}$ (Entradas 1 e 2, Tabela 9).

Tabela 9. Estudo comparativo entre $(R)-\mathbf{2}$ e CAB-33b em reações de adição das estananas 1a e 1c ao cicloexanocarboxialdeído 36. Adaptada da ref. 43

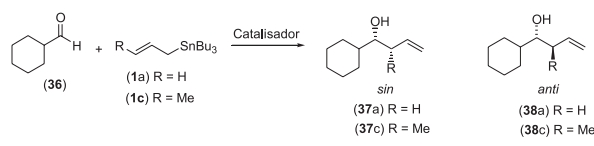

\begin{tabular}{lcccc}
\hline Entrada & Estanana & Catalisador & Rend. $(\%)$ & $\sin (e e \%) /$ anti $(e e \%)$ \\
\hline 1 & 1c & $(R)-2$ & 18 & $65(95) / 35(49)$ \\
2 & 1c & CAB-33b $^{\text {b }}$ & 71 & $93(93) / 7(80)$ \\
3 & 1a & $(R)-2$ & 53 & $(87)$ \\
4 & 1a & CAB-33b $^{\text {b }}$ & 42 & $(55)$ \\
\hline
\end{tabular}

a $20 \mathrm{~mol} \%(R)-\mathrm{BINOL}, 10 \mathrm{~mol} \% \mathrm{Ti}\left(\mathrm{O}^{\mathrm{P} P r}\right)_{4}, \mathrm{CH}_{2} \mathrm{Cl}_{2}$, peneira molecular $(4 \AA),-20{ }^{\circ} \mathrm{C}, 70$ h. $^{\mathrm{b}} 0,5$ equiv. CAB-33b, 1,0 equiv. estanana, 2,0 equiv. $\left(\mathrm{CF}_{3} \mathrm{CO}\right)_{2} \mathrm{O},-78{ }^{\circ} \mathrm{C}, 10 \mathrm{~h}$.

De maneira geral, os rendimentos obtidos empregando-se CAB33a e CAB-33b são moderados. Yamamoto e colaboradores ${ }^{44}$ avaliaram alguns ácidos borônicos como potenciais substitutos do $\mathrm{BH}_{3}$. THF de forma a aumentar a acidez de Lewis do CAB e a estereosseletividade da reação (Tabela 10).

A substituição da espécie de boro do $\mathrm{CAB}$ teve forte influência no rendimento químico e no excesso enantiomérico do aduto da alilação. O ácido 3,5-bis-(trifluorometil)-fenilborônico foi o mais
Tabela 10. Reações de alilação assimétrica catalisada por derivados de CAB. Adaptada da ref. 44

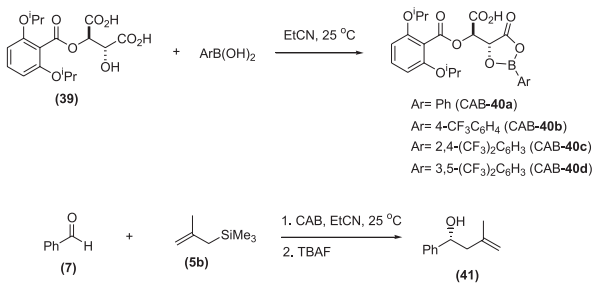

\begin{tabular}{lcccc}
\hline Entrada & $\mathrm{CAB}(\mathrm{mol} \%)$ & $\mathrm{T}\left({ }^{\circ} \mathrm{C}\right) ; \mathrm{t}(\mathrm{h})$ & Rend. $(\%)$ & $e e(\%)$ \\
\hline 1 & CAB-33b $(20)$ & $-78 ; 4$ & 68 & 82 \\
2 & CAB-40a $(20)$ & $-40 ; 5$ & 94 & 75 \\
3 & CAB-40b (20) & $-78 ; 6$ & 92 & 81 \\
4 & CAB-40c $(20)$ & $-78 ; 20$ & 83 & 89 \\
5 & CAB-40d (20) & $-70 ; 2$ & 99 & 88 \\
6 & CAB-40d $(10)$ & $-88 ; 4,5$ & 94 & 91 \\
7 & CAB-40d $(10)$ & $-78 ; 24$ & 96 & 86 \\
8 & CAB-40d $(10)$ & $-88 ; 22$ & 79 & 89 \\
\hline
\end{tabular}

efetivo para a reatividade (entrada 5, Tabela 10). A generalidade do método empregando o CAB-40d foi avaliada e observou-se em todos os casos um aumento dos rendimentos químicos, porém baixos níveis de excesso enantiomérico foram obtidos quando empregados aldeídos alifáticos (Esquema 11).

$$
\begin{aligned}
& \mathrm{R}_{\mathrm{H}}^{\stackrel{\mathrm{O}}{\mathrm{C}}+\mathrm{R}_{2 m}=\mathrm{R}^{1}} \mathrm{SiMe}_{3} \frac{1 . \mathrm{CAB}-40 \mathrm{~d}(20 \mathrm{~mol} \%), \mathrm{EtCN},-78^{\circ} \mathrm{C}}{2 \cdot \mathrm{TBAF}} \\
& \begin{array}{lll}
\mathrm{R}=\mathrm{Ph},(E)-\mathrm{PhCH}=\mathrm{CH} & (\mathbf{5 b}) \mathrm{R}^{1}=\mathrm{Me}, \mathrm{R}^{2}=\mathrm{H} & \sin \left(\mathrm{R}^{1}=\mathrm{Me}, \mathrm{R}^{2}=\mathrm{H}\right)
\end{array} \\
& \begin{array}{llc}
\mathrm{C}_{4} \mathrm{H}_{9}, \mathrm{C}_{5} \mathrm{H}_{11} & \sin \left(\mathrm{R}^{1}=\mathrm{Me}, \mathrm{R}^{2}=\mathrm{H}\right. \text { ) } \\
& \text { (5e) } \mathrm{R}^{1}=\mathrm{Me}, \mathrm{R}^{2}=\mathrm{Me} & \text { (Rend.: } 70-99 \% \text {; ee: } 63-88 \% \text { ) }
\end{array} \\
& \sin \left(\mathrm{R}^{1}=\mathrm{Me}, \mathrm{R}^{2}=\mathrm{Me}\right) \\
& \text { (Rend.: 56-82\%; ee: } 89-91 \% \text { ) }
\end{aligned}
$$

Esquema 11. Reações de alilação de aldeídos com alil-e crotilsilanos catalisadas por $C A B-40 d$

\section{Outros sistemas catalíticos}

Complexos de $\mathrm{Zn}(\mathrm{II})$ e bisoxazolinas quirais catalisaram a alilação de aldeídos em bons rendimentos, porém, com baixos níveis de enantiosseletividade ${ }^{45}$. Contudo, os complexos de Rh(III) com fenilbisoxazolinas (Phebox) apresentaram bons rendimentos e razoáveis enantiosseletividades ${ }^{46}$ (Tabela 11).

Para o catalisador 43, em todos os casos, o ataque se deu pela face $\mathrm{Si}$ do aldeído. Baseados em estudos de RMN e de raios-X os autores propõem a coordenação entre o oxigênio do composto carbonílico e o átomo metálico do complexo, de modo a minimizar a repulsão estérea (entre $\mathrm{H}$ formil e $\mathrm{Cl}$ apical) (Figura 16). Desta

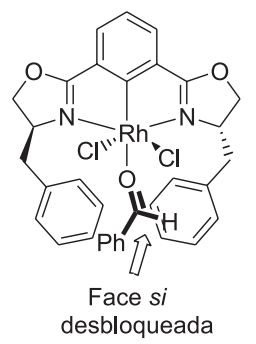

Figura 16. Estado de transição para a adição de alilestananas a aldeídos catalisada pelo complexo 43 conferindo enantiosseletividade à reação. Adaptada da ref. 46 
Tabela 11. Alilação enantiosseletiva de aldeídos promovida pelos catalisadores $\mathbf{4 2}$ ou $\mathbf{4 3}$. Adaptada da ref. 46

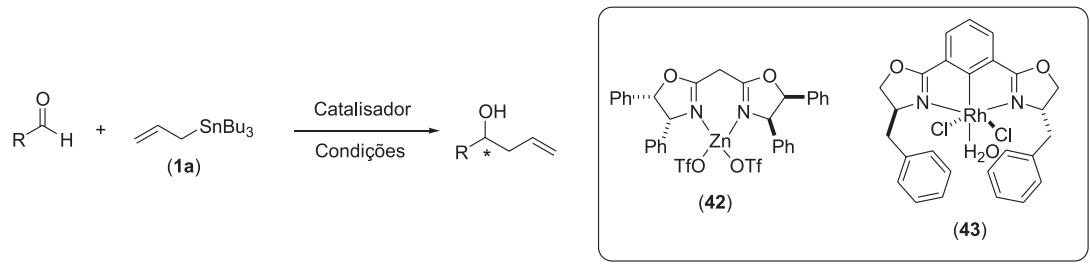

\begin{tabular}{|c|c|c|c|c|c|}
\hline Entrada & $\mathrm{R}$ & Catalisador & Condições & Rend. (\%) & $e e(\%)$ [Conf.] \\
\hline 1 & $\mathrm{c}-\mathrm{C}_{6} \mathrm{H}_{11}$ & 42 & A & 45 & $46[R]$ \\
\hline 2 & $(E)-\mathrm{PhCH}=\mathrm{CH}$ & 42 & A & 71 & $34[R]$ \\
\hline 3 & $(E)-\mathrm{PhCH}=\mathrm{CH}$ & 43 & B & 98 & $77[S]$ \\
\hline 4 & $\mathrm{Ph}$ & 42 & A & 80 & $35[R]$ \\
\hline 5 & $\mathrm{Ph}$ & 43 & B & 88 & $61[S]$ \\
\hline 6 & $4-\mathrm{MeO}-\mathrm{C}_{6} \mathrm{H}_{4}$ & 43 & B & 99 & $80[S]$ \\
\hline 7 & 2-furil & 43 & B & 94 & $58[S]$ \\
\hline
\end{tabular}

Condições A: 0,1 equiv. catalisador 42, 1,5 equiv. alilestanana (1a) e 1,0 equiv. do aldeído em diclorometano. Condição B: 0,05 equiv.

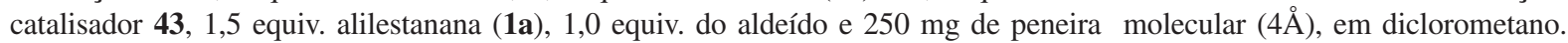

forma, apenas a face Si do aldeído encontra-se disponível para o ataque do nucleófilo, proporcionando enantiosseletividade à reação.

O uso de complexos de $\mathrm{Cr}$ (salen) em reações de alilação assimétrica e catalítica foi, primeiramente, descrito por UmaniRonchi e colaboradores ${ }^{47}$, porém, apenas moderados níveis de enantiosseletividade foram alcançados. Em 2005, Kwiatkowski e Jurczak $^{48}$ realizaram um estudo sistemático da reação de alilação catalítica e assimétrica de aldeídos na presença do complexo $(1 R, 2 R)-\mathbf{4 4}$ sob altas pressões. Uma gama de aldeídos (aromáticos, $\alpha, \beta$-insaturados, alifáticos primários a ramificados) foi testada, porém, rendimentos e enantiosseletividades moderados foram observados, sendo que os melhores resultados foram obtidos para aldeídos aromáticos e $\alpha, \beta$-insaturados (Esquema 12).

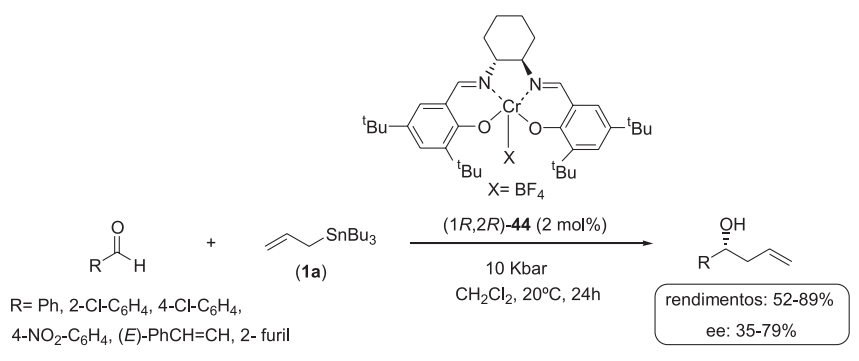

n-Bu, i-Pr, t-Bu, Cy

Esquema 12. Reações de alilação de aldeídos com aliltributilestanho (1a) catalisadas pelo complexo $(1 R, 2 R)-44$

Aplicações de reações de alilação catalítica assimétrica mediadas por ácidos de Lewis quirais na síntese de produtos naturais ou não-naturais

Na síntese do calolídeo A (45), Marshall e colaboradores ${ }^{49}$ compararam os sistemas catalíticos que empregam o complexo $(R)-\mathbf{2}^{8}$ e CAB-33a $\mathrm{a}^{40}$ no acoplamento entre o aldeído 46 e a estanana 47. Consistente com os estudos prévios, os autores observaram que o CAB-33a foi mais diastereo e enantiosseletivo que $(R)$-2 na formação do aduto sin 48a. Contudo, em ambos os casos, baixos rendimentos foram observados. O aduto 48a foi convertido no calolídeo A (45) após uma sequiência de etapas que envolveu a inversão do centro carbinólico (Esquema 13).

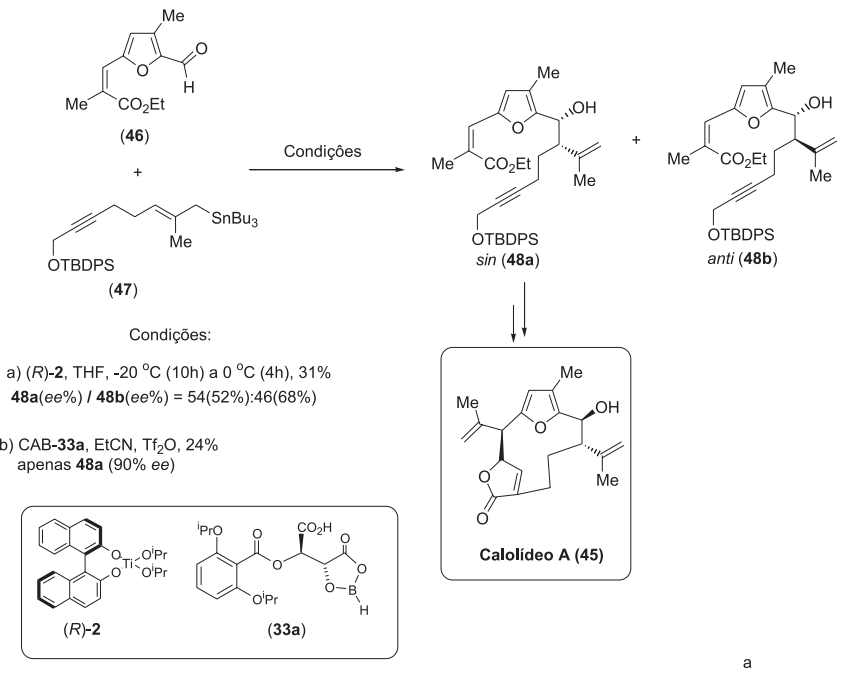

Esquema 13. Adição da estanana 47 ao aldeído 46 mediada pelo catalisador (R)-2 ou CAB-33a, segundo Marshall e colaboradores. Adaptado da ref. 49

Os sistemas desenvolvidos por Keck e colaboradores ${ }^{8}$ têm sido mais amplamente aplicados em síntese de produtos naturais, devido à facilidade de preparação do catalisador uma vez que o 1,1'binaftol é comercialmente disponível em suas duas formas enantioméricas. Evans e colaboradores ${ }^{50}$ utilizaram o sistema catalítico $(R)$-BINOL/Ti(IV) $[(R)$-2] na conversão do aldeído quiral 49 no álcool homoalílico $\mathbf{5 0} \mathrm{em}$ bom rendimento e alta diastereosseletividade. O álcool $\mathbf{5 0}$ foi posteriormente convertido na mucosina (51) (Esquema 14), um representante da classe de metabólicos secundários de Annonaceae ${ }^{51}$.

Roush e colaboradores ${ }^{52}$ empregaram o catalisador $(S)-\mathbf{2}$ desenvolvido por $\mathrm{Keck}^{8}$ na reação de alilação do $\beta$-alcoxialdeído $\mathbf{5 2}$ que forneceu o 1,3-sin diol 53, intermediário chave para obtenção do fragmento $\mathbf{5 4}$ do superstolídeo A (55) (Esquema 15). O diol 53 foi obtido em $79 \%$ de rendimento, em uma razão diastereoisomérica de $94: 6^{52}$.

O sistema catalítico $(R)$-Tol-BINAP/AgF, $[(R)-22]$ desenvolvido por Yamamoto e colaboradores ${ }^{34}$ foi utilizado por Shibasaki ${ }^{53}$ na síntese da formal da fostriecina (56), um metabólito de Streptomyces 

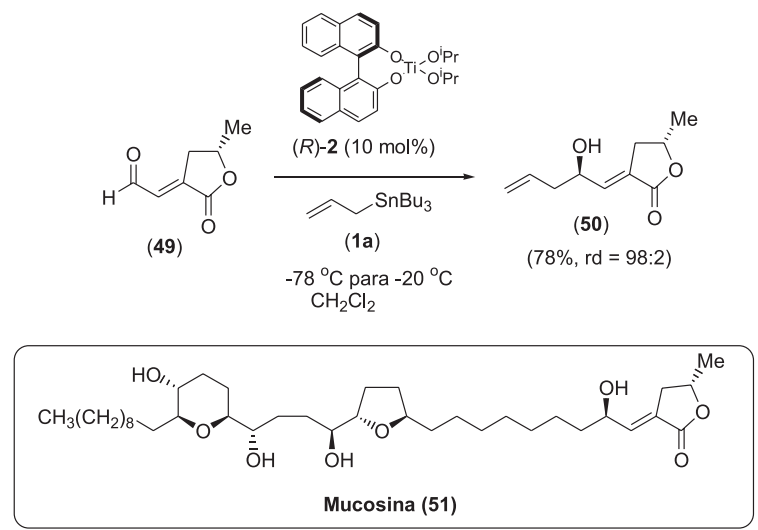

Esquema 14. Emprego do catalisador (R)-2 na alilação do aldeído 49 com aliltributilestanana (1a) para a síntese da mucosina (51), segundo Evans e colaboradores. Adaptado da ref. 50

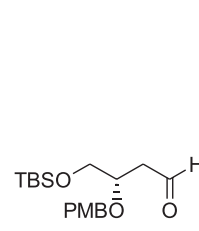

(52)
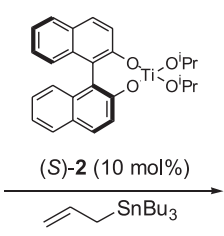

(1a)

$\mathrm{CH}_{2} \mathrm{Cl}_{2},-20^{\circ} \mathrm{C}$

6 dias
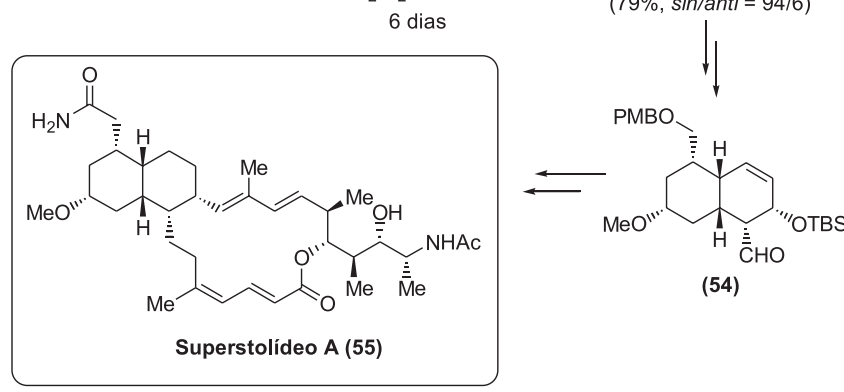

(54)

Esquema 15. Adição de aliltributilestanana (1a) ao aldeído 52, segundo Roush e colaboradores, na síntese do núcleo 54 do superstolídeo A (55). Adaptado da ref. 52

pulveraceus isolado em 1983, que apresenta atividade in vitro contra diversas linhagens de células cancerígenas e uma atividade inibitória elevada e seletiva para serina/treonina fosfatases (PP2A). A reação de alilação catalítica assimétrica entre o aldeído $\alpha, \beta$-insaturado 57 e o aliltrimetoxisilano (23a) forneceu o álcool 58 em bom rendimento e excelente razão diastereoisomérica que, após uma sequiência de etapas, foi convertido em $\mathbf{5 9}$, intermediário descrito por outros grupos na síntese da fostriecina ${ }^{54}$ (56) (Esquema 16).

Em 2003, Willis e colaboradores ${ }^{55}$ empregaram o catalisador $(S, S)$-11 desenvolvido por Maruoka ${ }^{25}$ na reação de alilação do 3,4diacetoxibenzaldeído (60) (Esquema 17). O álcool homoalílico 61 foi obtido em excelente rendimento e excesso enantiomérico. $\mathrm{O}$ sucesso desta reação possibilitou, após algumas etapas reacionais, a obtenção dos tetraidropiranos 62a e 62b, compostos isolados de extratos de Plectranthus sylvestris e que se apresentam como potentes antioxidantes in vitro.

Chandrasekhar e colaboradores ${ }^{56}$ descreveram a síntese estereosseletiva da piranona $\mathbf{6 7}$, um produto natural isolado a partir das folhas de Ravensara crassifolia, que apresentou atividade fungicida. O sucesso de sua abordagem deveu-se ao uso das metodologias de

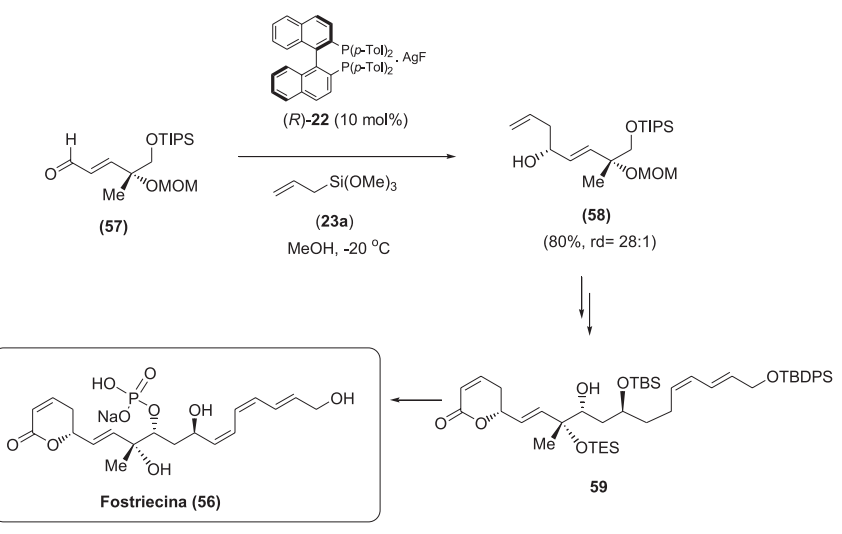

Esquema 16. Reação de alilação catalítica assimétrica entre o aldeído 57 e aliltrimetoxisilano (23a) na presença de $(R)-22$, segundo Shibasaki e colaboradores, na síntese do intermediário 58 na síntese formal da fostriecina (56). Adaptado da ref. 53

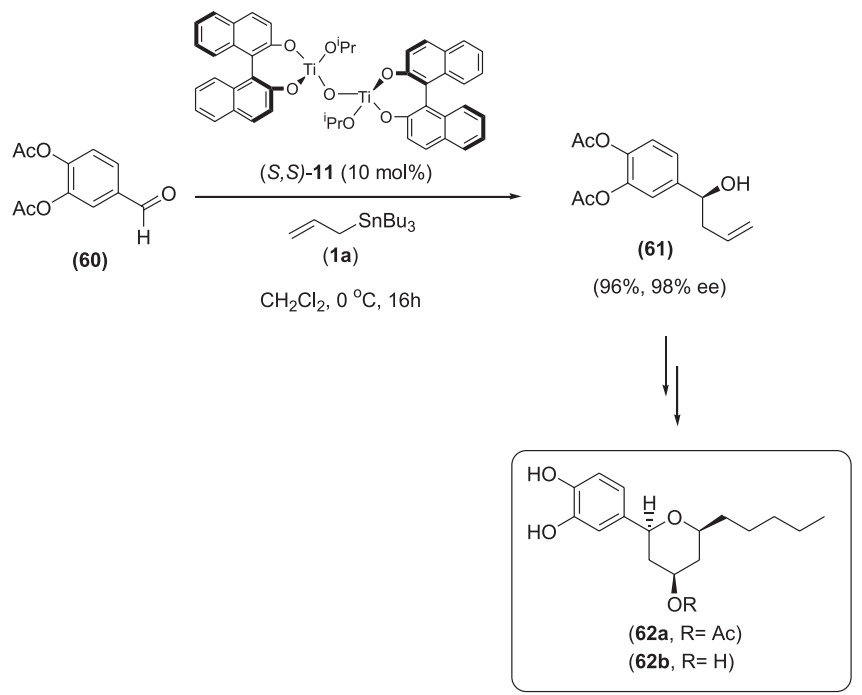

Esquema 17. Adição de aliltributilestanana (1a) ao aldeído 60, segundo Willis e colaboradores, na síntese do álcool $\mathbf{6 1}$ presente nos tetraidropiranos $\mathbf{6 2 a}$ e 62b. Adaptado da ref. 55

alilação estereosseletiva desenvolvidas por Maruoka ${ }^{25}$ e $\mathrm{Keck}^{8}$ que forneceram os respectivos álcoois homoalílicos 64 e 66, respectivamente, em bons rendimentos e estereosseletividade (Esquema 18).

Pilli e colaboradores ${ }^{57}$ descreveram a síntese total da $(R)$-argentilactona (70) e da $(R)$-goniotalamina (73) empregando o ácido de Lewis quiral desenvolvido por Maruoka e colaboradores ${ }^{25}$ (Esquema 19). Os álcoois homoalílicos 69 e 72 foram obtidos em bons rendimentos e excessos enantioméricos, o que viabilizou as sínteses destas piranonas naturais que apresentam reconhecida atividade antiproliferativa celular. A alilação enantiosseletiva do 2-octinal (68) representa, apesar dos grandes avanços nesta área, o primeiro exemplo do emprego de quantidade catalítica de ácidos de Lewis quirais para a adição de alil- $n$-tributilestanho a aldeídos propargílicos.

Este mesmo grupo, recentemente, descreveu a síntese total da $(R)$-fluoxetina. $\mathrm{HCl}^{58}$ (74), um inibidor potente e seletivo da recaptação da serotonina, em seis etapas, com $50 \%$ de rendimento total e $99 \%$ de excesso enantiomérico a partir do benzaldeído (7) via alilação catalítica assimétrica, empregando-se o catalisador desenvolvido por Maruoka e colaboradores ${ }^{25}$ (Esquema 20). 

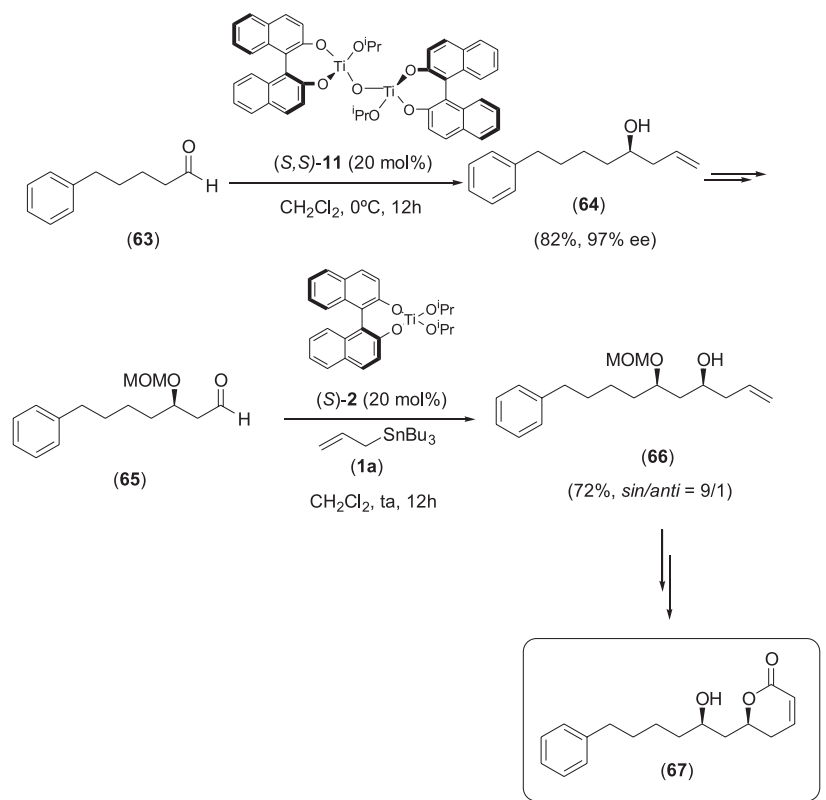

Esquema 18. Reações de alilação catalítica assimétrica na preparação da piranona 67. Adaptado da ref. 56
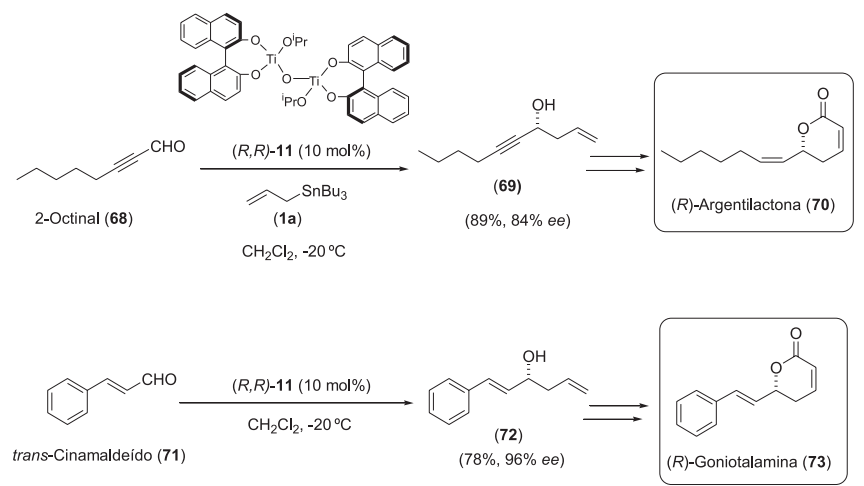

Esquema 19. Reações de alilação catalítica assimétrica na síntese total da $(R)$-argentilactona $(\mathbf{7 0})$ e da $(R)$-goniotalamina $(\mathbf{7 3})$, realizadas por Pilli e colaboradores. Adaptado da ref. 57

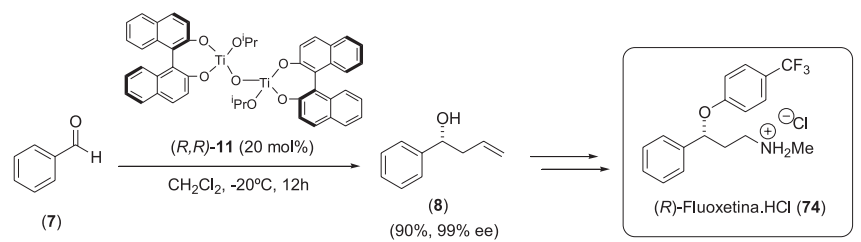

Esquema 20. Reação de alilação catalítica assimétrica na síntese total da (R)-fluoxetina.HCl (74) por Pilli e colaboradores. Adaptado da ref. 58

\section{ALILAÇÃO E CROTILAÇÃO CATALÍTICA ASSIMÉTRICA DE ALDEÍDOS MEDIADA POR BASES DE LEWIS}

\section{Ligantes baseados em fosforamidas quirais}

A alilação e crotilação de aldeídos utilizando-se alil- e crotilsiliconatos hipervalentes gerados pela adição de DMF ou HMPA a alil- e crotiltriclorosilanos foram independentemente demonstradas por Kobayashi ${ }^{59}$ e Denmark ${ }^{60,61}$.
Denmark relatou, em 1994, o primeiro exemplo de alilação assimétrica de aldeídos utilizando-se quantidades estequiométricas da fosforamida quiral $\mathbf{7 6}$ como base de Lewis ${ }^{60}$. Os álcoois homoalílicos derivados do benzaldeído (7) foram obtidos em bons rendimentos, mas em moderados níveis de enantiosseletividade (Tabela 12).

Tabela 12. Alilação enantiosseletiva do benzaldeído (7) promovida pela fosforamida quiral 76. Adaptada da ref. 60

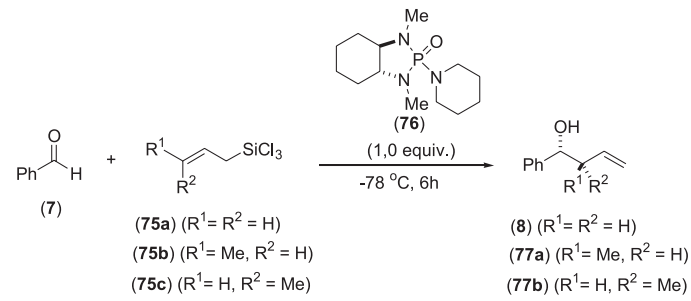

\begin{tabular}{llllll}
\hline Silano & \multicolumn{2}{c}{ Grupos } \\
& $\mathrm{R}^{1} \quad \mathrm{R}^{2}$ & Rend. sin/anti & Conf. & ee $(\%)$
\end{tabular}

\begin{tabular}{ccccccc}
\hline $\mathbf{7 5 a}$ & $\mathrm{H}$ & $\mathrm{H}$ & 81 & - & $R$ & 60 \\
$\mathbf{7 5 b}$ & $\mathrm{Me}$ & $\mathrm{H}$ & 68 & $2 / 98$ & $R, R$ & 66 \\
$\mathbf{7 5 c}$ & $\mathrm{H}$ & $\mathrm{Me}$ & 72 & $98 / 2$ & $R, S$ & 60 \\
\hline
\end{tabular}

O uso de quantidades subestequiométricas da fosforamida $\mathbf{7 6}$ foi acompanhado da redução da enantiosseletividade, evidenciando que vias menos seletivas estariam operando nestas condições. Estudos mecanísticos e cinéticos realizados por Denmark e colaboradores $^{62}$ revelaram que duas vias operavam na formação dos correspondentes álcoois homoalílicos: uma envolvendo duas moléculas de fosforamida ligadas ao silício (siliconato hexacoordenado) e outra, menos seletiva, onde apenas uma molécula de fosforamida (siliconato pentacoordenado) estaria ligada ao silício (Figura 17).

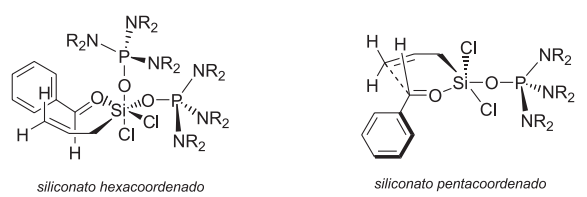

Figura 17. Estrutura dos possíveis estados de transição na formação dos álcoois homoalílicos envolvendo fosforamidas quirais

A participação de uma via menos seletiva comprometeria a enantiosseletividade do processo. Denmark, então, visualizou a possibilidade da utilização de bisfosforamidas quirais do tipo 78a-e (Figura 18), que aumentaria a concentração efetiva de uma segunda molécula do catalisador próximo ao átomo de silício ${ }^{62}$.

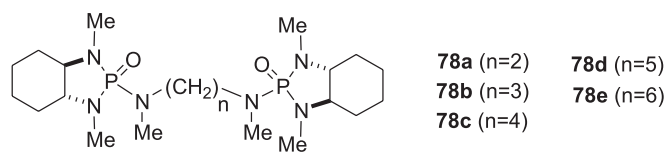

Figura 18. Estrutura das bisfosforamidas quirais 78a-e desenvolvidas por Denmark e colaboradores. Adaptada da ref. 62

Uma investigação sistemática revelou que a utilização da bisfosforamida 78d (em que as duas funções básicas são separadas por uma unidade de cinco grupos metilênicos, n=5) em 10 mol\% forneceu o correspondente álcool homoalílico derivado do benzaldeído em moderado excesso enantiomérico $(72 \%$ ee). As demais 
bisfosforamidas mostraram-se potencialmente inferiores na indução da enantiosseletividade (Tabela 13), provavelmente, por não atenderem aos requerimentos geométricos para alcançarem um arranjo cis à esfera de coordenação do silício.

Tabela 13. Adição do aliltriclorosilano (75a) ao benzaldeído (7) promovida pelas bisfosforamidas 78a-e. Adaptada da ref. 62

\begin{tabular}{|c|c|c|c|c|}
\hline Entrada & & & & \\
\hline & & & & \\
\hline 1 & $78 \mathbf{a}$ & 0,5 & 60 & 0 \\
\hline 2 & $78 b$ & 0,5 & 72 & 35 \\
\hline 3 & $78 \mathrm{c}$ & 0,5 & 82 & 17 \\
\hline 4 & $78 \mathrm{c}$ & 0,1 & 52 & 10 \\
\hline 5 & $78 d$ & 0,5 & 78 & 65 \\
\hline 6 & 78d & 0,1 & 54 & 72 \\
\hline 7 & $78 e$ & 0,5 & 75 & 46 \\
\hline
\end{tabular}

Análise de raios-X da estrutura cristalina do complexo 78d. $\mathrm{SnCl}_{4}$ revelou que a disposição interna do substituinte $\mathrm{N}$-metil estava fortemente associada ao esqueleto quiral da bisfosforamida ${ }^{63}$. Posteriores implementações no "design" de bisfosforamidas quirais foram realizadas com o objetivo de conferir maior rigidez ao nitrogênio do centro estereogênico, impondo uma maior assimetria à coordenação do aliltriclorosilano ${ }^{63}$ à base de Lewis quiral. Neste sentido, Denmark e colaboradores sintetizaram as bisfosforamidas quirais 79a-c (Figura 19).

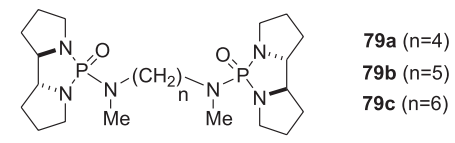

Figura 19. Estrutura das bisfosforamidas quirais 79a-c desenvolvidas por Denmark e colaboradores. Adaptada da ref. 63

Estas bisfosforamidas quirais, utilizadas em quantidade de 5 mol\%, induziram a adição do aliltriclorosilano (75a) ao benzaldeído (7) sendo observada uma seletividade superior para o dímero com um espaçador composto por 5 grupos metilênicos (79b) quando comparado às demais bisfosforamidas (Tabela 14).

Tabela 14. Alilação do benzaldeído (7) com o aliltriclorosilano (75a) catalisada pelos derivados 2,2'-bispirrolidinil-fosforamidas 79a-c. Adaptada da ref. 63

\begin{tabular}{|c|c|c|c|}
\hline Entrada & Catalisador & Rend. (\%) & $e e(\%)$ \\
\hline 1 & 79a & 54 & 18 \\
\hline 2 & 79b & 85 & 87 \\
\hline 3 & 79c & 58 & 67 \\
\hline
\end{tabular}

A bisfosforamida 79b foi eficiente na alilação de aldeídos aromáticos, heteroaromáticos e $\alpha, \beta$-insaturados, fornecendo os correspondentes álcoois homoalílicos em rendimentos razoáveis a excelentes (57-92\%) e em altos níveis de enantio- e diastereosseletividade $^{63}$ (Tabela 15).

O emprego de aliltriclorosilanos $\gamma$-substituídos (75b e 75c) forneceu os correspondentes álcoois homoalílicos em alta diastereos-
Tabela 15. Alilações catalisadas pela 2,2'-bispirrolidinilfosforamida (79b). Adaptada da ref. 63

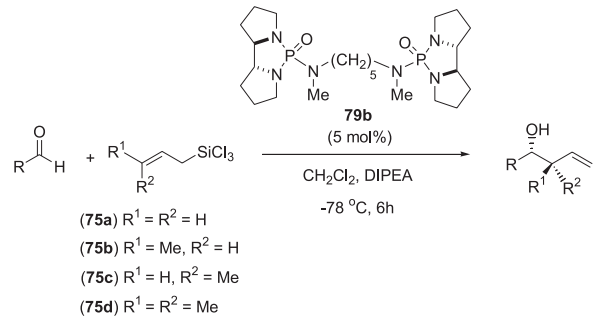

\begin{tabular}{lccccc}
\hline Entrada & Silano & $\mathrm{R}$ & $\begin{array}{c}\text { Rend. } \\
(\%)\end{array}$ & sin/anti & $\begin{array}{c}e e \\
(\%)^{\mathrm{c}}\end{array}$ \\
\hline 1 & $\mathbf{7 5 a}$ & $\mathrm{Ph}$ & 85 & - & 87 \\
2 & $\mathbf{7 5 a}$ & $4-\mathrm{CH}_{3} \mathrm{O}-\mathrm{C}_{6} \mathrm{H}_{4}$ & 84 & - & 88 \\
3 & $\mathbf{7 5 a}$ & $(E)-\mathrm{PhCH}_{4} \mathrm{CH}$ & 86 & - & 81 \\
4 & $\mathbf{7 5 a}$ & $2-$ furil & 59 & - & 81 \\
5 & $\mathbf{7 5 b}$ & $\mathrm{Ph}$ & 82 & $1 / 99$ & 86 \\
6 & $\mathbf{7 5 b}$ & $(E)-\mathrm{PhCH}=\mathrm{CH}$ & 57 & $1 / 99$ & 80 \\
7 & $\mathbf{7 5 c}$ & $\mathrm{Ph}$ & 89 & $99 / 1$ & 94 \\
8 & $\mathbf{7 5 c}$ & $4-\mathrm{CH}_{3} \mathrm{O}-\mathrm{C}_{6} \mathrm{H}_{4}$ & 91 & $99 / 1$ & 94 \\
9 & $\mathbf{7 5 c}$ & $(E)-\mathrm{PhCH}=\mathrm{CH}$ & 78 & $99 / 1$ & 88 \\
10 & $\mathbf{7 5 c}$ & $(E)-\mathrm{PhCH}=\mathrm{C}\left(\mathrm{CH}_{3}\right)$ & 62 & $95 / 5$ & 92 \\
11 & $\mathbf{7 5 c}$ & $2-$ furil & 82 & $99 / 1$ & 95 \\
12 & $\mathbf{7 5 d}$ & $\mathrm{Ph}$ & 89 & - & 96 \\
13 & $\mathbf{7 5 d}$ & $(E)-\mathrm{PhCH}=\mathrm{CH}$ & 70 & - & 88 \\
14 & $\mathbf{7 5 d}$ & $2-$ furil & 71 & - & 95 \\
\hline
\end{tabular}

seletividade (Tabela 15, entradas 7-14). A correlação entre a geometria do silano e a configuração relativa dos produtos $(E \rightarrow$ anti; $Z \rightarrow \sin$ ) reforça um estado de transição do tipo cadeira. Uma importante extensão da metodologia desenvolvida por Denmark e colaboradores foi a construção de centros estereogênicos quaternários. Assim, quando da utilização de aliltriclorosilanos $\gamma$-dissubstituídos não-simétricos $(E)-80$ e $(Z)-80$ obtiveram os respectivos álcoois homoalílicos 81a e 81b em bons rendimentos, alta relação sin/anti e altos excessos enantioméricos (Esquema 21). Apesar do sucesso obtido, apenas o benzaldeído (7) foi empregado como eletrófilo restringindo, desta maneira, a metodologia para a criação de centros estereogênicos quaternários $\alpha$-carbinólicos.
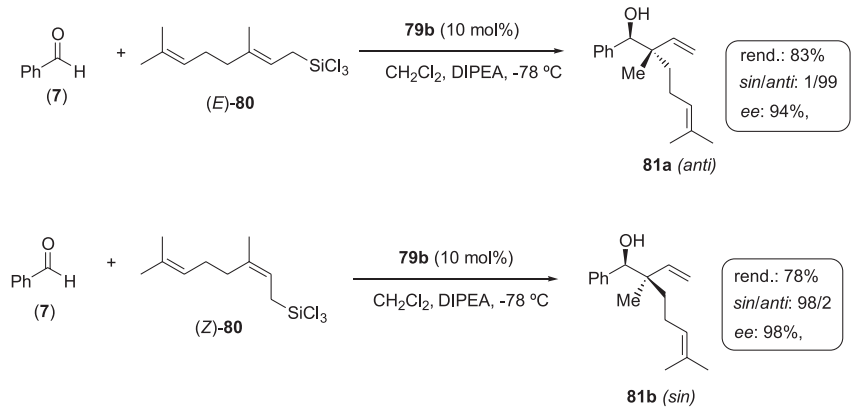

Esquema 21. Aplicação da metodologia desenvolvida por Denmark e colaboradores na construção de centros quaternários

Mecanisticamente, a metodologia desenvolvida por Denmark e colaboradores deve envolver um intermediário siliconato hexacoordenado com o átomo de silício em um arranjo octaédrico. $\mathrm{O}$ aldeído estaria coordenado ao silício e a transferência do grupo alil ocorreria através de um estado de transição cíclico altamente organizado, refletindo a informação da geometria da dupla ligação do 
silano na estereosseletividade dos centros estereogênicos formados no álcool homoalílico ${ }^{62}$ (Figura 20).

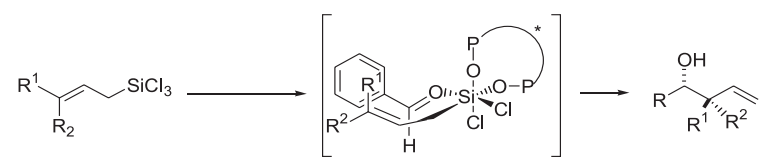

Figura 20. Proposta de estado de transição para reações de alilação de aldeídos catalisadas pelas bisfosforamidas quirais desenvolvidas por Denmark e colaboradores. Adaptada da ref. 62

Kobayashi e colaboradores descreveram o uso de fosforamidas quirais em reações de alilação e crotilação de aldeídos, em especial aldeídos aromáticos, com alta enantio- e diastereosseletividade ${ }^{64}$ (Tabela 16). As fosforamidas 82 e 83 foram preparadas a partir da $(S)$-2[( $\alpha$-naftilamino)-metil $]$ pirrolidina ${ }^{65}$ com o correspondente dicloreto fosforamídico, como descrito por Peyronel e colaboradores ${ }^{66}$, e suas configurações absolutas determinadas por cristalografia de raios-X.

Tabela 16. Alilação e crotilação de benzaldeído (7) utilizando-se quantidades sub-estequiométricas das fosforamidas quirais $\mathbf{8 2}$ e 83. Adaptada da ref. 64

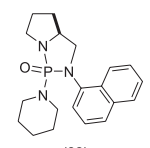

(82)
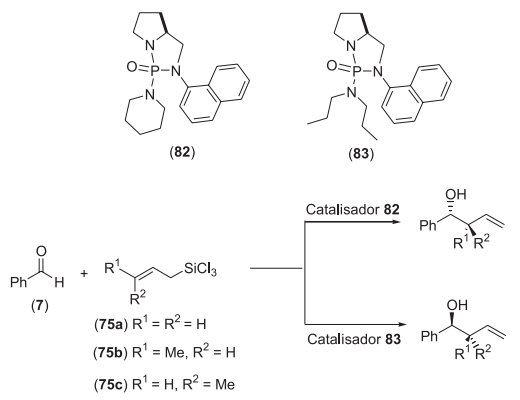

\begin{tabular}{lcccc}
\hline Entrada & Silano & $\begin{array}{c}\text { Catalisador } \\
(\mathrm{mol} \%)\end{array}$ & $\begin{array}{c}\text { Rend. }(\%) \\
{[\text { sin/anti] }}\end{array}$ & $\begin{array}{c}\text { ee }(\%) \\
{[\text { Config.] }}\end{array}$ \\
\hline 1 & $\mathbf{7 5 a}$ & $\mathbf{8 2}(10)$ & 67 & $85[R]$ \\
2 & $\mathbf{7 5 a}$ & $\mathbf{8 3}(10)$ & 83 & $88[S]$ \\
3 & $\mathbf{7 5 b}$ & $\mathbf{8 2}(20)$ & $68[3 / 97]$ & $73[1 R, 2 R]$ \\
4 & $\mathbf{7 5 b}$ & $\mathbf{8 3}(20)$ & $90[2 / 98]$ & $83[1 S, 2 S]$ \\
5 & $\mathbf{7 5 c}$ & $\mathbf{8 2}(20)$ & $95[98 / 2]$ & $76[1 R, 2 S]$ \\
6 & $\mathbf{7 5 c}$ & $\mathbf{8 3}(20)$ & $80[98 / 2]$ & $77[1 S, 2 R]$ \\
\hline
\end{tabular}

Uma interessante observação é a mudança das faces do aldeído e do silano quando são empregados os ligantes 82 e 83, porém até o presente momento não se conhece como os grupos ${ }^{n} \mathrm{Pr}$ e $-\left(\mathrm{CH}_{2}\right)_{5}$ influenciariam esta seleção de faces do composto carbonílico.

Em função da reconhecida facilidade do enxofre em coordenar-se a metais como cobalto, cobre, prata e zinco, Shi e colaboradores empregaram complexos de tiofosforamidas derivadas do $(R)$ 1,1'-binaftil-2,2'-diamina, $(R)-\mathbf{8 4}$, com triflato de prata (I), em reações de alilação assimétrica e catalítica do benzaldeído (7). Os resultados obtidos empregando-se $(R)$-84 mostraram-se superiores quando comparados com os ligante quiral $(1 S, 2 S)$-1,2-difeniletilenodiamina ${ }^{67},(1 S, 2 S)-85$ (Tabela 17) mas bastante inferiores aos demais sistemas catalíticos descritos anteriormente.

Utilizando uma abordagem semelhante, Nakajima e colaboradores $^{68}$ demonstraram o emprego de óxido de $(S)$-BINAP $[(S)$ BINAPO], $(S)-\mathbf{8 6}$, na presença de um sal de amônio quaternário em reações de alilação e crotilação de aldeídos. Os resultados mos- traram a baixa eficiência de $(S)$-86, principalmente, em relação aos níveis de enantiosseletividade obtidos (Tabela 18).

Tabela 17. Reações de alilação enantiosseletiva do benzaldeído (7) na presença dos ligantes $(R)-84$ e $(1 S, 2 S)-85$ em diferentes condições. Adaptada da ref. 67

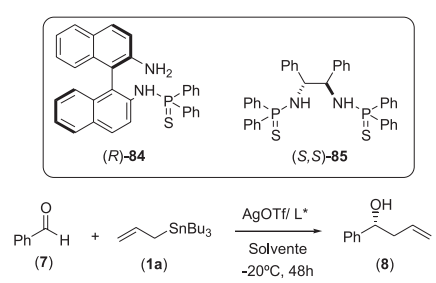

\begin{tabular}{lcccc}
\hline Entrada & L* & Solvente & Rend. (\%) & ee (\%) \\
\hline 1 & $(R)-\mathbf{8 4}$ & $\mathrm{THF}$ & 70 & 52 \\
2 & $(R)-\mathbf{8 4}$ & $\mathrm{CH}_{2} \mathrm{Cl}_{2}$ & 30 & 50 \\
3 & $(1 S, 2 S)-\mathbf{8 5}$ & $\mathrm{THF}^{2}$ & 70 & 15 \\
4 & $(1 S, 2 S)-\mathbf{8 5}$ & $\mathrm{CH}_{2} \mathrm{Cl}_{2}$ & 40 & 12 \\
\hline
\end{tabular}

Tabela 18. Reações de alilação enantiosseletiva do benzaldeído (7) catalisada por $(S)-86$ na presença de um sal de amônio quaternário. Adaptada da ref. 68

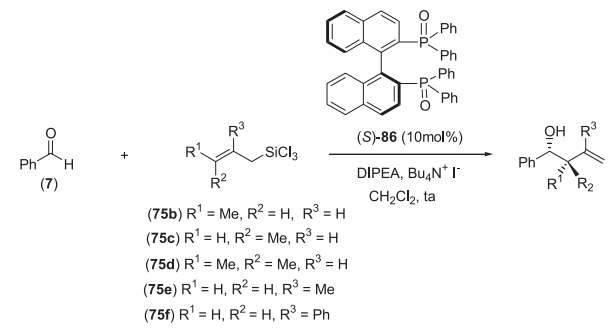

\begin{tabular}{lcccc}
\hline Entrada & Silano & Tempo (h) & Rend. (\%) & ee (\%) \\
\hline 1 & $\mathbf{7 5 b}$ & 2 & 87 & 46 \\
2 & $\mathbf{7 5 c}$ & 4 & 92 & 4 \\
3 & $\mathbf{7 5 d}$ & 4 & 63 & 4 \\
4 & $\mathbf{7 5 e}$ & 1 & 73 & 66 \\
5 & $\mathbf{7 5 f}$ & 1 & 80 & 59 \\
\hline
\end{tabular}

Neste mesmo trabalho os autores empregaram o sistema catalítico acima para a reação de alilação entre uma série de aldeídos e o alilsilano 75e. Apesar da melhora da enantiosseletividade quando comparada à Tabela 18, apenas aldeídos aromáticos e $\alpha, \beta$ insaturados foram empregados, demonstrando a limitação do método $^{68}$ (Esquema 22).

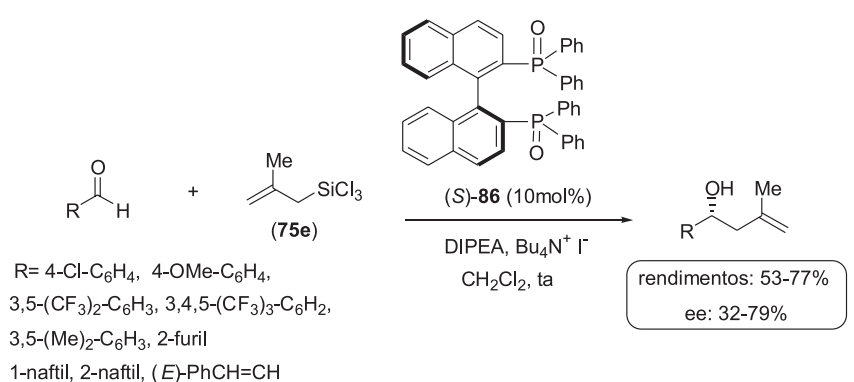

Esquema 22. Reações de alilação enantiosseletiva de aldeídos catalisadas por (S)-86 na presença de um sal de amônio quaternário 


\section{Ligantes baseados em formamidas quirais}

O uso de $N, N$-dimetilformamida como base de Lewis para catálise de reações de alilação foi descrito por Kobayashi e colaboradores ${ }^{59}$. Vários análogos quirais (87a-f) foram sintetizados e mostraram-se eficientes na reação de alilação de aldeídos ${ }^{69}$ (Figura 21).

$$
\begin{aligned}
& \text { (87a): } \mathrm{R}=\mathrm{Ph} \\
& \begin{array}{l}
(87 \mathrm{~b}): \mathrm{R}=4-\mathrm{CH}_{3} \mathrm{C}_{6} \mathrm{H}_{4} \\
(87 \mathrm{c}): \mathrm{R}=4-\mathrm{CF}_{3} \mathrm{C}_{6} \mathrm{H}_{4} \\
(87 \mathrm{~d}): \mathrm{R}=1 \text {-naftil } \\
(87 \mathrm{e}): \mathrm{R}=\text { cicloexil }
\end{array}
\end{aligned}
$$

Figura 21. Estruturas das formamidas quirais 87a-f desenvolvidas por Kobayashi e colaboradores. Adaptada da ref. 69

A formamida 87a mostrou-se superior quanto à estereosseletividade do processo, porém os níveis alcançados foram dependentes do aldeído e do aliltriclorosilano empregados (Tabela 19). O uso de HMPA mostrou-se essencial, aumentando os rendimentos químicos e a enantiosseletividade, mas a razão para tal ainda não

\begin{tabular}{|c|c|c|c|c|}
\hline Entrada & $\mathrm{R}$ & Silano & Rend. (\%) [sin/anti] & $e e(\%)$ \\
\hline 1 & $\mathrm{c}-\mathrm{C}_{5} \mathrm{H}_{9}$ & $75 a$ & 72 & 91 \\
\hline 2 & $\mathrm{PhCH}_{2} \mathrm{CH}_{2}$ & $75 a$ & 84 & 95 \\
\hline 3 & $\left(\mathrm{C}_{2} \mathrm{H}_{5}\right)_{2} \mathrm{CH}$ & $75 a$ & 74 & 93 \\
\hline 4 & $\mathrm{CH}_{2}=\mathrm{CHCH}_{2} \mathrm{CH}_{2}$ & $75 a$ & 56 & 86 \\
\hline 5 & c- $\mathrm{C}_{6} \mathrm{H}_{11}$ & $75 b$ & $92[>99 / 1]$ & $98^{\mathrm{a}}$ \\
\hline 6 & $\mathrm{PhCH}_{2} \mathrm{CH}_{2}$ & $75 b$ & $97[>99 / 1]$ & $94^{\mathrm{a}}$ \\
\hline 7 & $\mathrm{c}-\mathrm{C}_{6} \mathrm{H}_{11}$ & $75 c$ & 19 [64/40] & $98^{\mathrm{a}}$ \\
\hline 8 & $\mathrm{c}-\mathrm{C}_{6} \mathrm{H}_{11}$ & $75 \mathrm{c}$ & $34[5 / 95]^{\mathrm{b}}$ & $3^{\mathrm{a}}$ \\
\hline
\end{tabular}
está esclarecida. Diferentemente quando foram empregados 75a e 75b, a metodologia não forneceu bons rendimentos e níveis de estereosseletividade com o uso do aliltriclorosilano $\mathbf{7 5 c}$.

Tabela 19. Alilação e crotilação catalítica e estereosseletiva de aldeídos mediadas pela formamida 87a. Adaptada da ref. 69

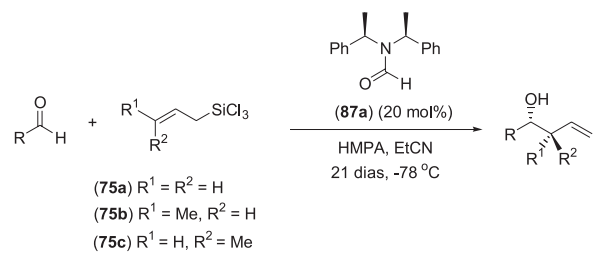

${ }^{\mathrm{a}} \mathrm{O}$ valor de $e e$ é referente ao produto majoritário. ${ }^{\mathrm{b}}$ Esta reação foi realizada à $-20^{\circ} \mathrm{C}$.

\section{Ligantes baseados em $N$-óxidos de bisquinolinas e de bipiridinas quirais}

Nakajima e colaboradores introduziram, em 1997, o uso de $N, N$ '-dióxidos derivados da $(S)$-3,3'-dimetil-2,2'-bisquinolina, $(S)$ 88, como catalisadores em reações de alilação enantiosseletiva de aldeídos $^{70}$ (Tabela 20).

O protocolo desenvolvido por Nakajima e colaboradores mostrou-se eficiente para a alilação de aldeídos aromáticos e $\alpha, \beta$ insaturados (entradas 1-4 e 7-10, Tabela 20), porém, foi ineficiente para aldeídos alifáticos (entradas 5 e 6, Tabela 20). A alilação do benzaldeído com $(E)$ - e $(Z)$-crotiltriclorosilanos forneceu os res-
Tabela 20. Alilação enantiosseletiva de aldeídos com aliltriclorosilanos catalisada pelo complexo $(S)-\mathbf{8 8}$. Adaptada da ref. 70

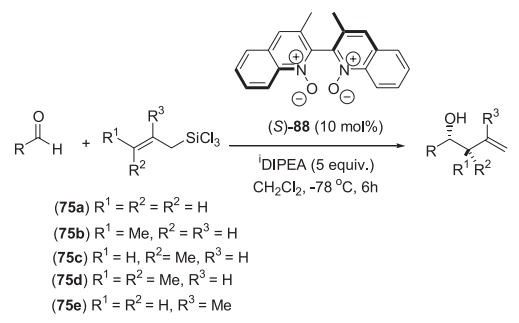

\begin{tabular}{lcccc}
\hline Entrada & $\mathrm{R}$ & Silano & $\begin{array}{c}\text { Rendimento (\%) } \\
{[\text { sin/anti] }}\end{array}$ & $\begin{array}{c}\text { ee }(\%) \\
{[\text { Config. }]}\end{array}$ \\
\hline 1 & $\mathrm{Ph}$ & $\mathbf{7 5 a}$ & 85 & $88[R]$ \\
2 & $4-\mathrm{MeO}-\mathrm{C}_{6} \mathrm{H}_{4}$ & $\mathbf{7 5 a}$ & 91 & $92[R]$ \\
3 & $2-\mathrm{Me}-\mathrm{C}_{6} \mathrm{H}_{4}$ & $\mathbf{7 5 a}$ & 70 & $90[R]$ \\
$4^{\mathrm{a}}$ & $(\mathrm{E})-\mathrm{PhCH}=\mathrm{CH}$ & $\mathbf{7 5 a}$ & 87 & $80[R]$ \\
5 & $\mathrm{PhCH}_{2} \mathrm{CH}_{2}$ & $\mathbf{7 5 a}$ & 30 & $7[S]$ \\
6 & $\mathrm{C}_{6} \mathrm{C}_{11}$ & $\mathbf{7 5 a}$ & 27 & $28[S]$ \\
7 & $\mathrm{Ph}$ & $\mathbf{7 5 b}$ & $68[3 / 97]$ & $86[1 R, 2 R]$ \\
8 & $\mathrm{Ph}$ & $\mathbf{7 5 c}$ & $64[99 / 1]$ & $84[1 R, 2 S]$ \\
9 & $\mathrm{Ph}$ & $\mathbf{7 5 d}$ & 52 & $78[R]$ \\
10 & $\mathrm{Ph}$ & $\mathbf{7 5 e}$ & 70 & $49[R]$ \\
\hline
\end{tabular}

${ }^{a}$ Foram empregados $20 \mathrm{~mol} \%$ do catalisador.

pectivos álcoois homoalílicos anti e sin, respectivamente (entradas 7 e 8, Tabela 20). Assim, como proposto por Denmark e colaboradores $^{62}$, os autores também sugerem que a alilação de aldeídos aromáticos e $\alpha, \beta$-insaturados mediada por $(S)$-88 se processa via um estado de transição cíclico do tipo Zimmerman-Traxler envolvendo um siliconato hipervalente em que um dos oxigênios do $\mathrm{N}$-óxido ocupa uma posição axial (Figura 22).

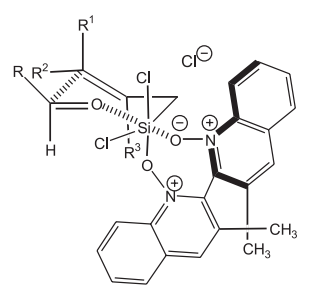

Figura 22. Estado de transição do tipo Zimmerman-Traxler para reações de alilação mediada por (S)-88

De acordo com este modelo de estado de transição, a baixa enantiosseletividade observada para o silano 75e (entrada 10, Tabela 20) pode ser entendida como resultado das repulsões estéreas do tipo 1,3-diaxial entre o grupo metila e uma unidade biaril do ligante.

Hayashi e colaboradores desenvolveram um novo ligante, $(R)$ 89, com uma altíssima atividade catalítica $(0,01$ a $0,1 \mathrm{~mol} \%$ do catalisador pode ser empregado), que é preparado sem a necessidade de resolução óptica ${ }^{71}$ (tanto os ligantes desenvolvidos por Denmark e Nakajima envolvem uma etapa de resolução em suas abordagens de preparação) uma vez que a quiralidade apresentada pelo novo ligante foi originada do $(R)$-BINOL empregado na preparação do $(R)-89^{71}$. O novo ligante quiral $(R)-89$ exibe alta atividade catalítica provavelmente, segundo os autores, por efeitos $\pi-\pi$-"stacking" entre o grupo fenila presente no ligante e o anel aromático do aldeído, que estabilizariam o estado de transição (Esquema 23). Não são fornecidos resultados para outros aldeídos que não aromáticos. 


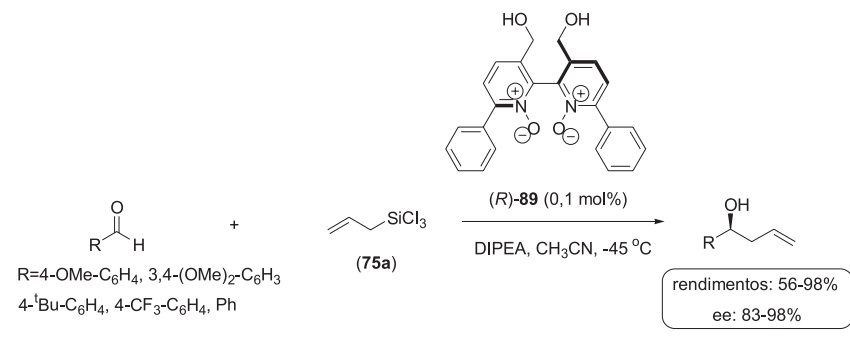

Esquema 23. Alilação assimétrica de aldeídos aromáticos com aliltriclorosilano (75a) catalisada por $(R)-89$

O emprego de $\mathrm{N}$-óxidos derivados de 2,2'-bipiridinas quirais, PINDOX-90a e PINDOX-90b, mostrou altos níveis de enantiosseletividade em reações de alilação de aldeídos ${ }^{72}$ (Tabela 21). Os resultados obtidos foram melhores para aldeídos aromáticos quando comparados a aldeídos alifáticos, demonstrando o efeito benéfico da conjugação $\pi$, como também observado por Hayashi e colaboradores ${ }^{71}$.

Tabela 21. Alilação assimétrica de aldeídos aromáticos com aliltriclorosilano (75a) catalisada por PINDOX-90a ou PINDOX90b. Adaptada da ref. 72

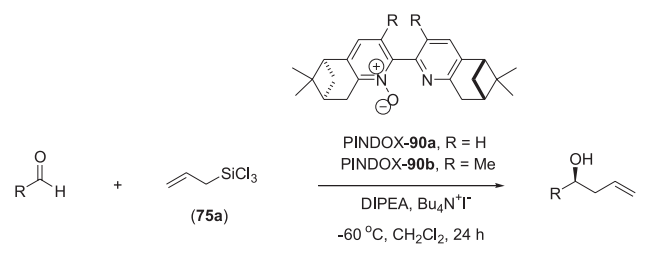

\begin{tabular}{lcccc}
\hline Entrada & $\mathrm{R}$ & Catalisador & Rend. (\%) & ee (\%) \\
\hline 1 & $\mathrm{Ph}$ & $\mathbf{9 0 a}$ & 78 & 90 \\
2 & 4-Me- $\mathrm{C}_{6} \mathrm{H}_{4}$ & $\mathbf{9 0 a}$ & 71 & 87 \\
3 & $2-$-naftil & $\mathbf{9 0 a}$ & 85 & 88 \\
4 & $(E)-\mathrm{PhCH}_{4} \mathrm{CH}$ & $\mathbf{9 0 a}$ & 56 & 77 \\
5 & $\mathrm{PhCH}_{2} \mathrm{CH}_{2}$ & $\mathbf{9 0 a}$ & 44 & 49 \\
6 & ${\mathrm{C}-\mathrm{C}_{6} \mathrm{H}_{11}}_{7}$ & $\mathbf{9 0 a}$ & 10 & $4^{\mathrm{a}}$ \\
7 & $\mathrm{Ph}$ & $\mathbf{9 0 b}$ & 72 & 98 \\
8 & 2-naftil & $\mathbf{9 0 b}$ & 55 & 91 \\
\hline
\end{tabular}

a A configuração absoluta não foi determinada.

No estado de transição, o controle estereoeletrônico requer que o grupo N-O se coordene trans ao grupo alil em relação ao silício, de forma a aumentar a nucleofilicidade do alilsilano. $\mathrm{O}$ aldeído, então, coordena-se cis ao grupo alil via um intermediário em que o silício se encontra hexacoordenado ${ }^{73}$ (Figura 23). Estudos mecanísticos e de modelagem molecular sugerem que enquanto o grupo $\mathrm{N}$ -

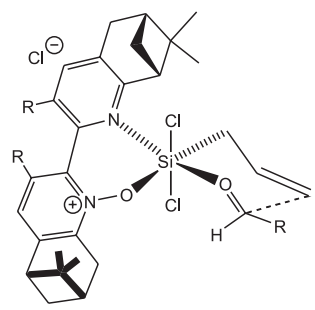

Figura 23. Estrutura do intermediário proposto por Kocovsky e colaboradores, envolvido na reação de alilação assimétrica catalisada pelo PINDOX-90a e PINDOX-90b. Adaptada da ref. 72
O do ligante ativa o alilsilano, o outro átomo de nitrogênio estabiliza o intermediário por quelação.

\section{Aplicações de reações de alilação catalítica assimétrica mediadas por bases de Lewis quirais na síntese de produtos naturais ou não-naturais}

Em contraste ao uso de reações de alilação de aldeídos catalisadas por ácidos de Lewis quirais como estratégia principal em sínteses de produtos naturais ou não-naturais, o emprego desta classe de reações catalisadas por bases de Lewis quirais em sínteses assimétricas ainda não foi muito explorada.

Recentemente, Denmark e colaboradores ${ }^{74}$ demonstraram a aplicação da metodologia desenvolvida por eles na síntese dos antagonistas da serotonina ${ }^{75}$, 94a e 94b (LY426965), que estruturalmente contém um centro estereogênico quaternário $\alpha$ ao grupo carbonílico. Na síntese de 94a, a instalação deste centro ocorreu pela adição do silano (E)-91 ao benzaldeído (7) na presença de $10 \mathrm{~mol} \%$ do $(S, S)$ 79b. O álcool homoalílico 92 foi obtido em bom rendimento e altos níveis de excesso diastereo- e enantiomérico e, posteriormente, foi convertido em 94a. A limitação da metodologia foi evidenciada na síntese de 94b, quando o cicloexanocarboxialdeído (36) foi submetido às condições de alilação o álcool desejado 95 não foi formado. Como alternativa, 92 foi convertido no intermediário 93 após seqüência reacional e a síntese de 94b (LY426965) pôde ser concluída (Esquema 24).
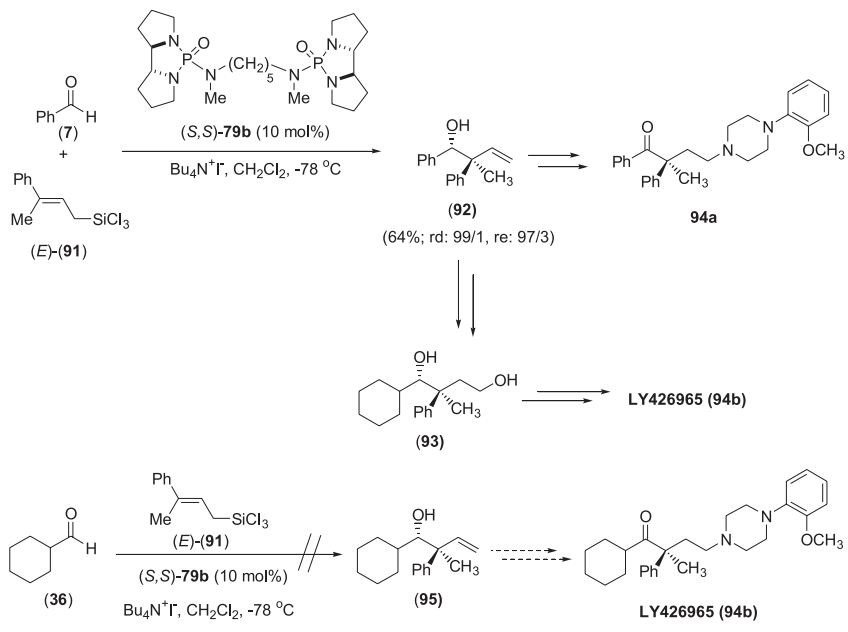

Esquema 24. Instalação do centro quaternário $\alpha$ ao grupo carbonílico durante a sintese de 94 a e $94 \mathbf{b}$, segundo Denmark e colaboradores. Adaptado da ref. 74

\section{CONCLUSÕES E PERSPECTIVAS}

O que foi aqui apresentado exemplifica bem o desenvolvimento de ácidos e bases de Lewis quirais que modulam a atividade catalítica controlando o ambiente quiral em reações de alilação e crotilação de aldeídos, permitindo a obtenção dos produtos desejados em altos níveis de estereosseletividade. Quando comparadas aos exemplos de alilação e crotilação catalítica assimétrica de aldeídos mediados por ácidos de Lewis quirais, as reações empregando bases de Lewis quirais encontram-se menos exploradas, pois os primeiros exemplos surgiram na década de 90, mas apresentam potencial para a formação de centros estereogênicos quaternários.

Os sistemas que empregam os complexos metálicos de Ti(IV) e $\mathrm{Zr}(\mathrm{IV})$ e ligantes BINOL ou BINAP apresentam altos níveis de 
enantiosseletividade para a adição de alilsilanos e alilestananas a aldeídos.

O uso de complexos BINAP/Ag(I) ou $p$-Tol-BINAP/Ag(I) também se mostrou eficiente, porém a informação da geometria da dupla ligação do crotilsilano é perdida, observando-se apenas a formação do aduto anti. Os catalisadores baseados em aciloxiboranas quirais $(\mathrm{CAB})$ fornecem bons níveis de enantiosseletividade e diferentemente dos sistemas BINAP/Ag(I) ou $p$-Tol-BINAP/Ag(I), as aciloxiboranas fornecem o aduto $\sin$ a partir tanto de $(E)$ - como de $(Z)$-silanos.

Complexos de $\mathrm{Zn}(\mathrm{II})$ e $\mathrm{Rh}(\mathrm{III})$ tendo bisoxalozinas quirais como ligantes, assim como $\mathrm{Cr}$ (salen), foram recentemente testados para esta classe de reações, porém, os resultados obtidos com o uso destes complexos não são muito promissores.

A utilização de bases de Lewis quirais mostrou-se mais interessante quando comparada com os ácidos de Lewis, uma vez que o emprego de $(E)$ - e (Z)-triclorosilanos forneceu os adutos sin e anti, respectivamente, em altos níveis de enantiosseletividade. As bisfosforamidas quirais desenvolvidas por Denmark e colaboradores permitiram a geração de centros estereogênicos quaternários, ainda que de uma forma restrita ao uso de benzaldeído como reagente eletrofílico.

Os ligantes baseados em $N$-óxidos e $N, N$-dióxidos de bisquinolinas quirais apresentaram, em especial os $N$-óxidos, alta atividade catalítica $(0,1 \mathrm{~mol} \%$ do ligante foi empregado), porém o método parece estar restrito a aldeídos aromáticos.

Em sua maioria, as metodologias de alilação catalítica assimétrica empregando ácidos e bases de Lewis quirais apresentam melhores rendimentos e níveis de enantiosseletividade quando são empregados aldeídos aromáticos e/ou $\alpha, \beta$-insaturados em comparação aos aldeídos alifáticos.

O desenvolvimento de novos sistemas catalíticos capazes de maximizar rendimentos e níveis de estereosseletividade (tanto para aldeídos aromáticos e $\alpha, \beta$-insaturados como para alifáticos), o uso de outros compostos eletrofílicos (cetonas e iminas) e o emprego desta metodologia na síntese de moléculas de maior complexidade estrutural podem ser apontados como os desafios nesta crescente área da síntese orgânica.

\section{AGRADECIMENTOS}

À Fundação de Amparo à Pesquisa do Estado de São Paulo (FAPESP) e ao Conselho Nacional para o Desenvolvimento Científico e Tecnológico $(\mathrm{CNPq})$ pelo apoio financeiro.

\section{REFERÊNCIAS}

1. Síntese ideal é aquela em que a molécula alvo é preparada, a partir de matérias-primas disponíveis, em uma única etapa (operacionalmente simples, segura e ambientalmente aceitável) e que ocorre rapidamente e de forma quantitativa. Para ler mais sobre síntese ideal, ver Wender, P. A. Em Organic Synthesis. Theory and Applications; Hudlicky, T., ed.; Jai Press, 1993.

2. Dentre os 12 princípios que devem ser considerados na implementação da química verde em uma indústria ou instituição de ensino e/ou pesquisa, inclui-se o uso de catalisadores (tão seletivos quanto possível) em substituição aos reagentes estequiométricos sempre que possível. Para saber mais sobre a utilização e prevenção de poluição, ver Sheldon, R. A.; Chem. Ind. 1997, 12; Sime, J. T.; J. Chem. Educ. 1999, 76, 1658.

3. Para revisões recentes em reações de alilação assimétrica e catalítica, ver Yanagisawa, A. Em Comprehensive Asymmetric Catalysis, Jacobsen, E. N.; Pfaltz, A.; Yamamoto, H., eds.; Sprinher-Verlag: Heidelberg, 1999, cap. 27; Cozzi, P. G.; Tagliavini, E.; Umani-Ronchi, A.; Gazz. Chim. Ital. 1997, 127, 247; Denmark, S. E.; Fu, J.; Chem. Rev. 2003, 103, 2763.

4. Yamamoto, Y.; Yatagai, H.; Naruta, Y.; Maruyama, K.; J. Am. Chem. Soc. 1980, 102, 7107; Yamamoto, Y.; Yatagai, H.; Ishihara, Y.; Mada, N.; Maruyama, K.; Tetrahedron 1984, 40, 2239
5. Para um modelo cíclico semelhante envolvendo o $\mathrm{ZnCl}_{2}$ em uma alilação anti-seletiva de aldeídos com alilestananas $\gamma$-substituída, ver Nishigaichi, Y.; Takuwa, A.; Chem. Lett. 1994, 1429.

6. Keck, G. E.; Krishnamurthy, D.; Grier, M. C.; J. Org. Chem. 1993, 58, 6543.

7. Costa, A. L.; Piazza, M. G.; Tagliavani, E.; Trombini, C.; Umani-Ronchi, A.; J. Am. Chem. Soc. 1993, 115, 7001 .

8. Keck, G. E.; Tarbet, K. H.; Geraci, L. S.; J. Am. Chem. Soc. 1993, 115, 8467; Keck, G. E.; Geraci, L. S.; Tetrahedron Lett. 1993, 34, 7827.

9. Doucet, H.; Santelli, M.; Tetrahedron: Asymmetry 2000, 11, 4163.

10. Weigand, S.; Brückner, R.; Chem. Eur. J. 1996, 2, 1072.

11. Yu, C. -M.; Choi, H. -S.; Jung, W. -H.; Lee, S. -S.; Tetrahedron Lett. 1996, 37, 7095 .

12. Yu, C. -M.; Choi, H. -S.;Yoon, S. -K.; Jung, W. -H.; Synlett 1997, 889.

13. Yu, C. -M.; Choi, H. -S.; Jung, W. -H.; Kim, H. -J.; Lee, S. -S.; Bull. Korean. Chem. Soc. 1997, 18, 471.

14. Yu, C. -M.; Choi, H. -S.; Jung, W. -H.; Kim, H. -J.; Shin, J.; Chem. Commun. 1997, 761

15. Gauthier Jr.; D. R.; Carreira, E. M.; Angew. Chem., Int. Ed. 1996, 35, 2363.

16. A adição de aliltrimetilsilano a vários eletrófilos tem se mostrado ser $10^{3}$ a $10^{4}$ mais lenta que a da correspondente aliltrimetilestanana. Para uma escala de nucleofilicidade e eletrofilicidade, ver Mayr, H.; Patz, M.; Angew. Chem., Int. Ed. 1994, 33, 938.

17. Yamago, S.; Furukawa, M.; Azuma, A.; Yoshida, J. -I.; Tetrahedron Lett. 1998, 39, 3783.

18. A palavra polímero foi criada por Berzelius em 1832 para designar compostos de pesos moleculares elevados que variam de $10^{3}$ a $10^{8}$. Polímeros dendríticos são polímeros altamente ramificados (o nome é derivado do grego "dendron" que significa árvore). Para saber mais sobre o tema, ver Mano, E. B.; Mendes, L. C.; Introdução a polímeros, Ed. Edgar Blücher, 2 ed. 1999, cap. 1.; Carraher Jr., C. E.; Polymer chemistry: an introduction, $4^{\text {th }}$ ed., 1996, p. 348.

19. Bardjí, M.; Caminade, A. -M.; Majoral, J. -P.; Chaudret, B.; Organometallics 1997, 16, 3489.

20. Beat, P. B.; Seebach, D.; Polym. Mater. Sci. Eng. 1997, 77, 130; Butz, T.; Murer, P.; Seebach, D.; Polym. Mater. Sci. Eng. 1997, 77, 132.

21. Chow, H.; Mak, C. C.; J. Org. Chem. 1997, 62, 5116.

22. Gorman, C. B.; Parkhurst, B. L.; Su, W. Y.; Chen, K. -Y.; J. Am. Chem. Soc. 1997, 119, 1141; Issberner, J.; Vögtle, F.; De Cola, L.; Balzani, V.; Chem. Eur. J. 1997, 3, 706.

23. Kii, S.; Maruoka, K.; Tetrahedron Lett. 2001, 42, 1935; Hanawa, H.; Kii, S.; Maruoka, K.; Adv. Synth. Catal. 2001, 343, 57.

24. Marshall, J. A.; Chemtracts-Organic Chemistry 1996, 9, 280 e referências citadas.

25. Hanawa, H.; Hashimoto, T.; Maruoka, K.; J. Am. Chem. Soc. 2003, 125, 1706; Konishi, S.; Hanawa, H.; Maruoka, K.; Tetrahedron: Asymmetry 2003, 14, 1603; Hanawa, H.; Uraguchi, D.; Konishi, S.; Hashimoto, T.; Maruoka, K.; Chem. Eur. J. 2003, 9, 4405.

26. Bedeschi, P.; Casolari, S.; Costa, A. L.; Tagliavini, E.; Umani-Ronchi, A.; Tetrahedron Lett. 1995, 36, 7897.

27. Casolari, S.; Cozzi, P. G.; Orioli, P.; Tagliavini, E.; Umani-Ronchi, A.; Chem. Commun. 1997, 2123.

28. Kurosu, M.; Lorca, M.; Tetrahedron Lett. 2002, 43, 1765.

29. Para revisões sobre amplificação assimétrica, ver Kagan, H. B.; Girard, C.; Guillaneux, D.; Rainford, D.; Samuel, O.; Zhang, S. Y.; Zhao, S. H.; Acta Chem. Scandin. 1996, 50, 345; Avalos, M.; Babiano, R.; Cintas, P.; Jiménez, J. L.; Palácios, J. C.; Tetrahedron: Asymmetry 1997, 8, 2997; Girard, C.; Kagan, H. B.; Angew. Chem., Int. Ed. 1998, 37, 2922; Feringa, B. L.; van Delden, R. A.; Angew. Chem., Int. Ed. 1999, 38, 3418; Mikami, K.; Terada, M.; Korenaga, T.; Matsumoto, Y.; Ueki, M.; Angelaud, R.; Angew. Chem., Int. Ed. 2000, 39, 3532.

30. Faller, J. W.; Sams, D. W. I.; Liu, X.; J. Am. Chem. Soc. 1996, 118, 1217.

31. Sasai, H.; Suzuki, T.; Itoh, N.; Tanaka, K.; Date, T.; Okamura, K.; Shibasaki, M.; J. Am. Chem. Soc. 1993, 115, 10372; Boyle, T. J.; Eilerts, N. W.; Heppert, J. A.; Takusagawa, F.; Organometallics 1994, 13, 2218.

32. Corey, E. J.; J. Org. Chem. 1990, 55, 1693.

33. Yanagisawa, A.; Nakashima, H.; Ishiba, A.; Yamamoto, H.; J. Am. Chem. Soc., 1996, 118, 4723; Yanagisawa, A.; Nakashima, H.; Nakatsuka, Y.; Ishiba, A.; Yamamoto, H.; Bull. Chem. Soc. Jpn. 2001, 74, 1129.

34. Yanagisawa, A.; Kageyama, H.; Nakatsuka, Y.; Asakawa, K.; Matsumoto, Y.; Yamamoto, H.; Angew. Chem., Int. Ed. 1999, 38, 3701.

35. Keck, G. E.; Savin, K. A.; Cressman, E. N. K.; Abbott, D. E.; J. Org. Chem. 1994, 59, 7889.

36. Para uma revisão recente sobre reações orgânicas estereosseletivas em água, ver Lindström, U. M.; Chem. Rev. 2002, 102, 2751.

37. Loh, T. -T.; Zhou, J. -R.; Tetrahedron Lett. 2000, 41, 5261.

38. Wadamoto, M.; Ozasa, N.; Yanagisawa, A.; Yamamoto, H.; J. Org. Chem. 2003, 68, 5593 . 
39. Wang, C-J; Shi, M.; Eur. J. Org. Chem. 2003, 2823.

40. Furuta, K.; Mouri, M.; Yamamoto, H.; Synlett 1991, 561.

41. Yamamoto, Y.; Yatagi, H.; Ishikaro, Y.; Maeda, N.; Maruayama, K.; Tetrahedron 1984, 40, 2239

42. Marshall, J. A.; Tang, Y.; Synlett 1992, 653.

43. Marshall, J. A.; Palovich, M. R.; J. Org. Chem. 1998, 63, 4381.

44. Ishihara, K.; Mouri, M.; Gao, Q.; Maruayama, T.; Furuta, K.; Yamamoto, H.; J. Am. Chem. Soc. 1993, 115, 11490.

45. Cozzi, P. G.; Orioli, P.; Tagliavini, E.; Umani-Ronchi, A.; Tetrahedron Lett. 1997, 38, 145.

46. Motoyama, Y.; Narusawa, H.; Nishiyama, H.; Chem. Commun. 1999, 131; Motoyama, Y.; Okano, M.; Narusawa, H.; Makihara, N. Aoki, K.; Nishiyama, H.; Organometallics 2001, 20, 1580.

47. Bandini, M.; Cozzi, P. G.; Umani-Ronchi, A.; Tetrahedron 2001, 57, 835.

48. Kwiatkowski, P.; Jurcsak, J.; Synlett 2005, 227.

49. Marshall, J. A.; Liao, J.; J. Org. Chem. 1998, 63, 5962.

50. Evans, P. A.; Murthy, V. S.; Tetrahedron Lett. 1998, 39, 9627.

51. Para uma revisão recente sobre acetogeninas de Annonaceae, ver Alali, F. Q.; Liu, X. -X.; McLaughlin, J. L.; J. Nat. Prod. 1999, 62, 504

52. Roush, W.; Chanpoux, J. A.; Peterson, B. C.; Tetrahedron Lett. 1996, 37, 8989.

53. Fujii, K.; Maki, K.; Kanai, M.; Shibasaki, M.; Org. Lett. 2003, 5, 733.

54. Chavez, D. E.; Jacobsen, E. N.; Angew. Chem., Int. Ed. 2001, 40, 3667.; Miyashita , K.; Ikejiri, M.; Maemura, S.; Imanishi, T.; Chem. Commun. 2002, 742.; Esumi, T. Okamoto, N.; Hatakeyama, S.; Chem. Commun. 2002, 3042.

55. Crosby, S. R.; Harding, J. R.; King, C. D.; Parker, G. D.; Willis, C. L.; Org. Lett. 2002, 4, 3407.

56. Chandrasekhar, S.; Narsihmulu, C.; Shameem, S.; Reddy, M. S.; Tetrahedron Lett. 2004, 45, 9299.

57. de Fátima, A.; Pilli, R. A.; Tetrahedron Lett. 2003, 44, 8721; de Fátima, A.; Kohn, L. K.; Antonio, M. A.; Pilli, R. A.; Bioorg. Med. Chem. 2004, 12, 5437; de Fátima, A.; Kohn, L. K.; Antonio, M. A.; de Carvalho, J. E.; Pilli, R. A.; Bioorg. Med. Chem. 2005, 13, 2927.

58. de Fátima, A.; Lapis, A. A. M.; Pilli, R. A.; J. Braz. Chem. Soc. 2005, 16, 495.

59. Kobayashi, S.; Nishio, K.; Tetrahedron Lett. 1993, 34, 3453; Kobayashi, S.; Nishio, K.; Synthesis 1994, 457; Kobayashi, S.; Nishio, K.; J. Org. Chem. 1994, 59, 6620; Kobayashi, S.; Nishio, K.; J. Am. Chem. Soc. 1995, 117,6392 .
60. Denmark, S. E.; Coe, D. M.; Pratt, N. E.; Griedel, B. D.; J. Org. Chem. 1994, 59, 6161 .

61. Denmark, S. E.; Fu, J.; Chem. Commun. 2003, 167.

62. Denmark, S. E.; Fu, J.; J. Am. Chem. Soc. 2000, 122, 12021.

63. Denmark, S. E.; Fu, J.; J. Am. Chem. Soc. 2001, 123, 9488.

64. Iseki, K.; Kuroki, Y.; Takahashi, M.; Kobayashi, Y.; Tetrahedron Lett. 1996, 37, 5149; Iseki, K.; Kuroki, Y.; Takahashi, M.; Kishimoto, S.; Kobayashi, Y.; Tetrahedron 1997, 53, 3513.

65. Asami, M.; Ohno, H.; Kobayashi, S.; Mukaiyama, T.; Bull. Chem. Soc. Jpn. 1978, 51, 1869.

66. Peyronel, J. -F.; Samuel, O.; Fiaud, J. -C.; J. Org. Chem. 1987, 52, 5320.

67. Shi, M.; Sui, W. -S.; Tetrahedron: Asymmetry 2000, 11, 773.

68. Nakajima, M.; Kotani, S.; Ishizuka, T.; Hshimoto, S.; Tetrahedron Lett. $\mathbf{2 0 0 5}, 46,157$.

69. Iseki, K.; Mizumo, S.; Kuroki, Y.; Kobayashi, Y.; Tetrahedron Lett. 1998 39, 2767; Iseki, K.; Mizumo, S.; Kuroki, Y.; Kobayashi, Y.; Tetrahedron 1999, 55, 977 .

70. Nakajima, M.; Sasaki, Y.; Shiro, M.; Hashimoto, S.; Tetrahedron: Asymmetry 1997, 8, 341; Nakajima, M.; Saito, M.; Shiro, M.; Hashimoto, S.; J. Am. Chem. Soc. 1998, 120, 6419; Nakajima, M.; Sasaki, Y.; Iwamoto, H.; Hashimoto, S.; Tetrahedron Lett. 1998, 39, 87; Nakajima, M.; Saito, M.; Hashimoto, S.; Chem. Pharm. Bull. 2000, 48, 306.

71. Shimada, T.; Kina, A.; Ikeda, S.; Hayashi, T.; Org. Lett. 2002, 4, 2799.

72. Malkov, A. V.; Bella, M.; Langer, V.; Kocovsky, P.; Org. Lett. 2000, 2, 3047; Malkov, A. V.; Baxendale, I. R.; Fawcett, J.; Russel, D. R.; Langer, V.; Mansfield, D. J.; Valko, M.; Kocovsky, P.; Organometallics 2001, 20, 673; Malkov, A. V.; Orsini, M.; Pernazza, D.; Muir, K. W.; Langer, V.; Meghani, P.; Kocovsky, P.; Org. Lett. 2002, 4, 1047.

73. Complexos hexacoordenados de $N, N$-monóxidos derivados de piridinas bidentadas com metais como cobre(I) e cobalto (II) foram discutidos por Anderson, R. J.; Hagback, P. H.; Steel, P. J.; Inorg. Chim. Acta 1999, 284, 273; Vrbová, M.; Baran, P. Boca, R.; Fuess, H.; Svoboda, I.; Linert, W.; Schubert, U.; Wiede, P.; Polyhedron 2000, 19, 2195.

74. Denmark, S. E.; Fu, J.; Org. Lett. 2002, 4, 1951.

75. Antagonista é o fármaco ou composto-protótipo que apresenta efeitos fisiológicos ou farmacológicos opostos a um outro. Ao nível do biorreceptor, é a entidade química que bloqueia as respostas associadas ao agonista que no caso em questão é o neurotransmissor serotonina. 